IDENTITY DEVELOPMENT AND BELONGING OF FIRST NATIONS WOMEN FROM GEORGINA ISLAND

by

Carolynne Warton, BA, Ryerson University, 2009

\author{
A Major Research Paper \\ presented to Ryerson University \\ in partial fulfillment of the \\ requirements for the degree of \\ Master of Arts \\ in the program of \\ Early Childhood Studies
}

Toronto, Ontario, Canada, 2010

(C) Carolynne Warton 2010 


\section{AUTHOR'S DECLARATION}

I hereby declare that I am the sole author of this major research paper.

I authorize Ryerson University to lend this paper to other institutions or individuals for purpose of scholarly research.

Signature

I further authorize Ryerson to reproduce this paper by photocopying or by other means, in total or in part, at the request of other institutions or individuals for the purpose of scholarly research.

Signature 


\title{
IDENTITY DEVELOPMENT AND BELONGING OF FIRST NATIONS WOMEN FROM GEORGINA ISLAND
}

\author{
(c) Carolynne Warton, 2010 \\ Master of Arts \\ Early Childhood Studies \\ Ryerson University
}

\begin{abstract}
This study explores the effects of the Indian Act and Bill C-31 on the identity development and sense of belonging felt by the women from Georgina Island First Nation. The purpose of this study is to give a voice to the First Nations women from Georgina Island whose identity and lives have been impacted by this legislation. The framework and methodology that guided this research was respectful of the indigenous knowledge and traditions of this community. The vision of the community and the participants was the most important focus of this study. The sharing which took place provided insight into the how it felt for the women to have their identity removed by the Canadian Government, the challenges that the removal created within the community, what it felt like to have that identity 'given' back, how important community is and what these women wish for our future generations.
\end{abstract}

KEY WORDS: Indigenous and Aboriginal, First Nations, identity, Indian Act, Bill C-31, community, belonging 


\section{ACKNOWLEDGEMENTS}

I would firstly like to recognize my community, Georgina Island First Nation for their support and patience with me throughout my educational journey.

To those who shared and participated in this project, I appreciate all your time, knowledge and sharing. This would not have been possible without you all.

A special Chi Miigwetch to Dr. Lynn Lavallee for her support, guidance and wisdom throughout my journey through graduate school. I can't express how lucky I feel to have been guided towards her. Lynn opened my eyes to meaningful research and allowed me to work in a way that felt right for my community and myself. I am forever grateful.

I am honoured to have had Dr. Rachel Berman guide and support me during this process. You were a great support and I appreciate all your time, experience and knowledge. I feel honoured that you were a part of this process. Chi Miigwetch

I would like to extend my love and thankfulness to my husband Chris, children Kyle and Olivia, Auntie and lifelong friend Shannon for all their support during my return to school.

Lastly, I would like to recognize my mom Heather who has always believed in me and encouraged me throughout my schooling. Thank you for your support and for being our glue. This wouldn't have been possible without you.

Thank you. 


\section{DEDICATIONS}

This paper is dedicated to the memory of my Dad and my Grandma Edna whose belief in our community gives me hope and strength.

Dad, as I write my final words I can feel your pride in my accomplishment.

Menoni (Grandma Edna), your memory lives on in the hearts of many.

Your strength and determination for this community to be strong and proud gives me the courage and determination to fight for our children and their ancestral connections. 


\section{FOREWORD}

\section{Social Location}

When working with an indigenous framework and within a First Nations community it is customary for the researcher to introduce themselves and describe their social location (Lavallee, 2007). I am an Anishnaabe (Ojibway) woman who grew up within the First Nations community that has been chosen for the study - Georgina Island. I believe it is my responsibility as a community member and graduate student to focus my studies on my community and invest my knowledge where it will have the most meaning. My worldview is a holistic one, recognizing multiple realities. I believe that people are influenced by their ancestors and everything around them and that they cannot separate themselves from that, nor should they want to.

As a child, I was unaware of the separation of members within my community due to the enforcement of status and non-status 'Indians" through the Canadian government's legislation known as the Indian Act (1876), which governs and regulates the lives of Indigenous peoples in Canada and dictates to them their ability to live within their community. Everyone growing up in the community had status, though I now understand this was due to the need to have status in order to own a home within the community. My closest friend lived off the reserve but visited often and her mom and Granny were from the community. I grew up thinking that her family lived on the 'mainland' because they wanted to. It was not until I was a young teenager in 1985 and Bill-C31 was introduced that I became aware of the government's influence on who belonged and who did not. After 1985 many new people began moving into the First Nations community. As a young adult I found this exciting.

As a researcher I hope to give the stories of this community a voice, to raise awareness as to the challenges that the women of Georgina Island have faced in developing their identity as 
Anishnaabe women, and encourage the community to provide an environment were all can grown in a place free of spiritual, emotional, physical, and mental exclusion.

In short, the focus of this research has come out of my life experience and a curiosity to understand the impact that the legislation has played on the identity and sense of belonging for First Nations people from my community. 


\section{TABLE OF CONTENTS}

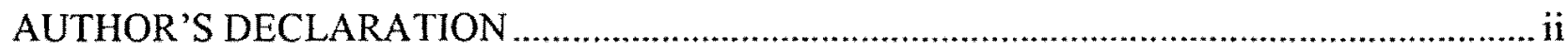

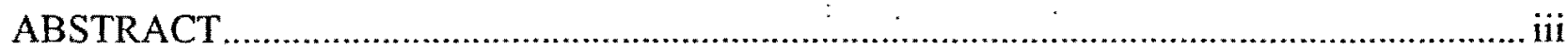

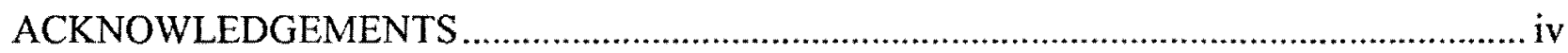

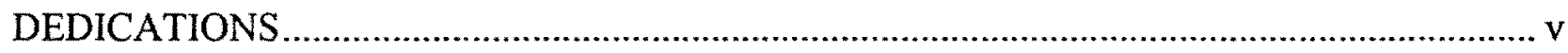

FORWORD

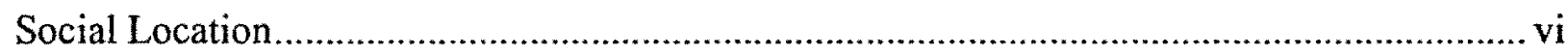

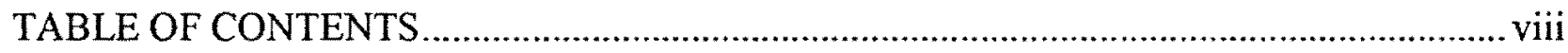

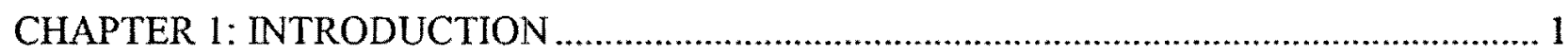

Identity Development of First Nations Women from Georgina Island .................................... 1

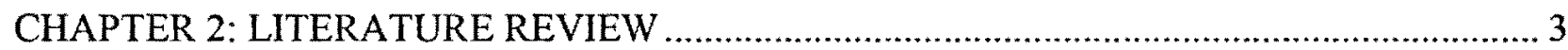

The Effects of Legislation on Identity Development …........................................................... 3

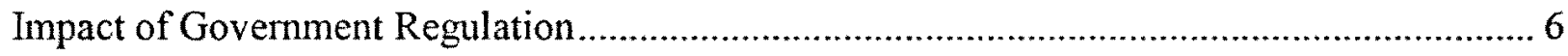

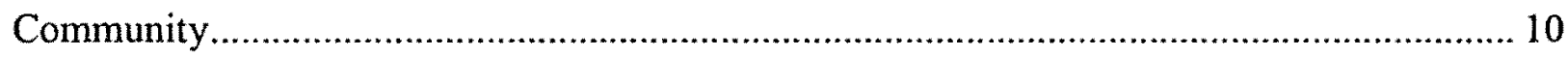

Power

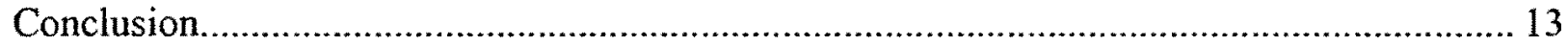

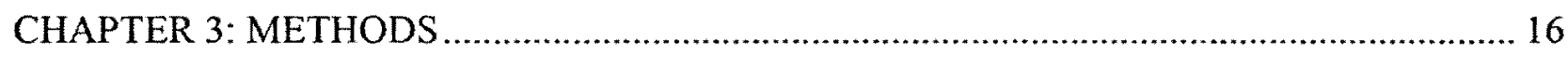

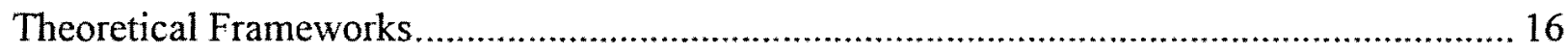

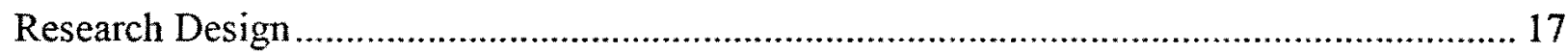

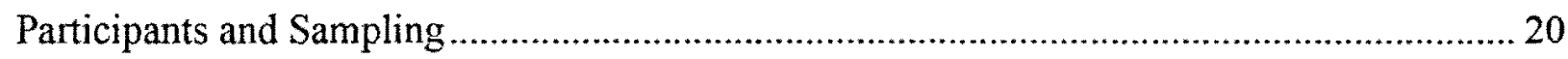

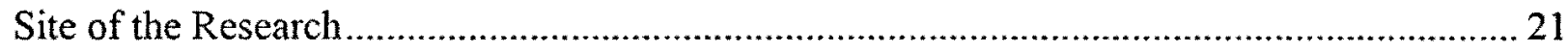

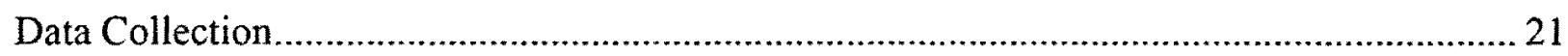

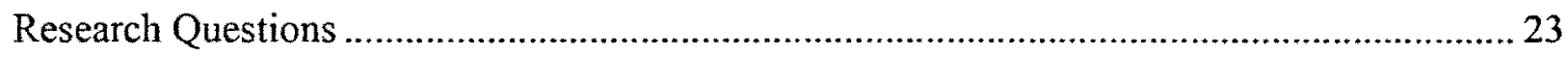

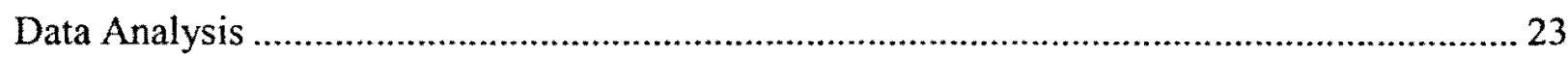

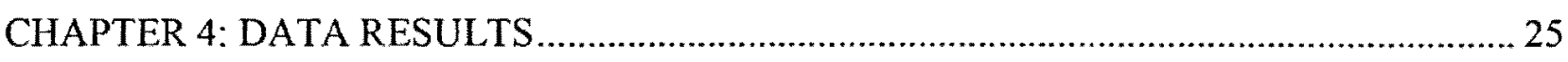

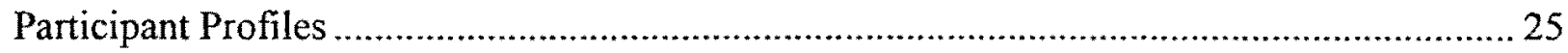

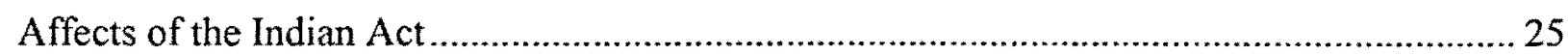

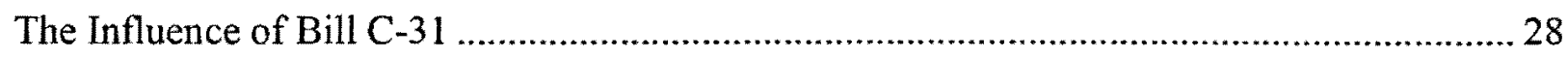

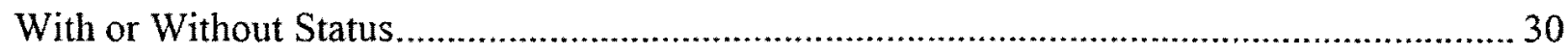

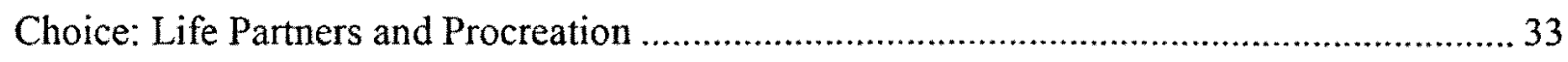

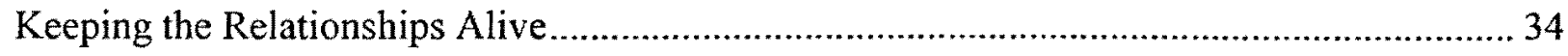




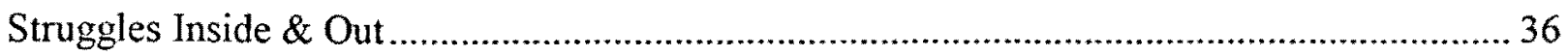

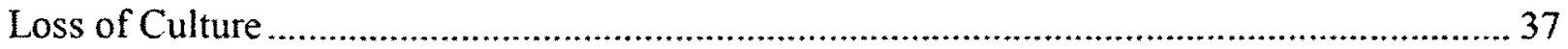

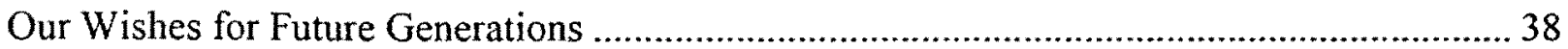

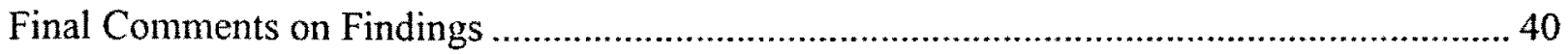

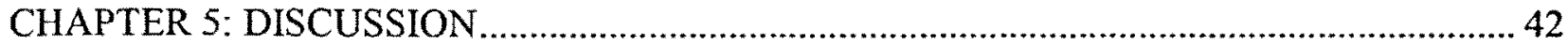

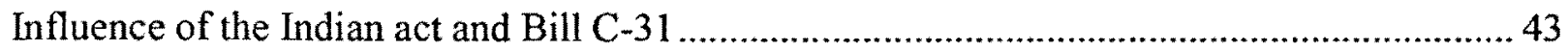

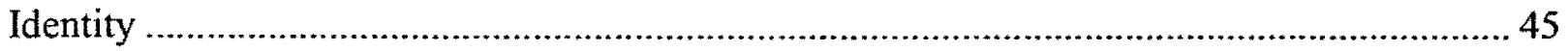

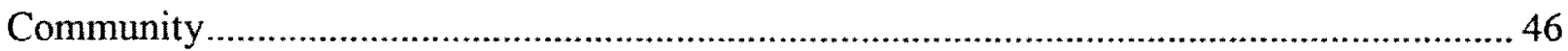

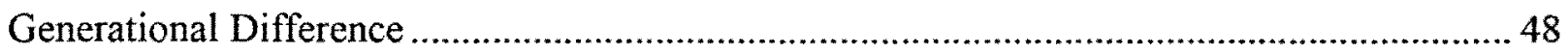

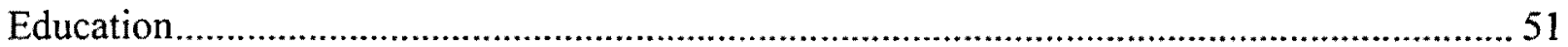

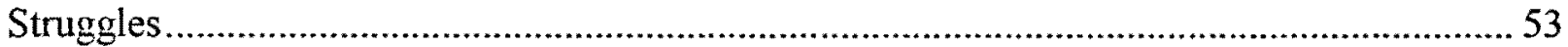

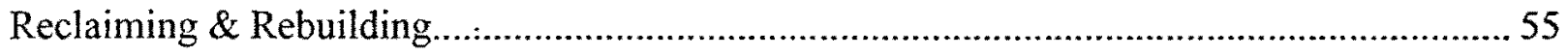

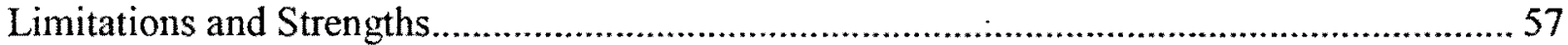

CHAPTER 6: CONCLUSION AND RECOMMENDATIONS ….............................................5

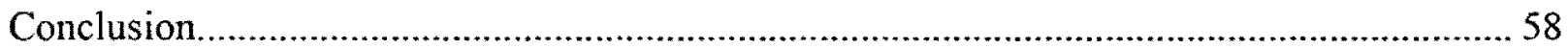

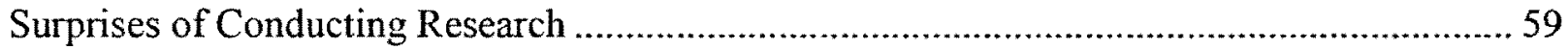

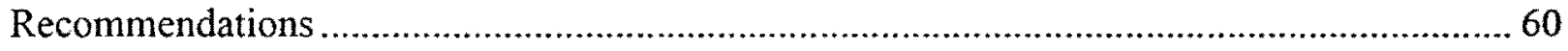

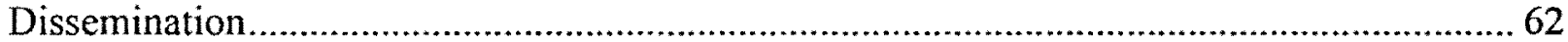

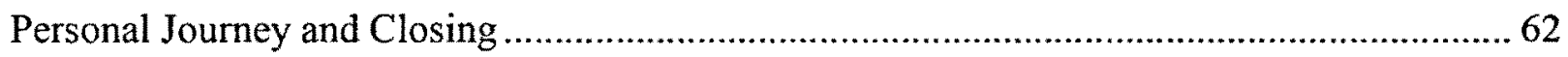

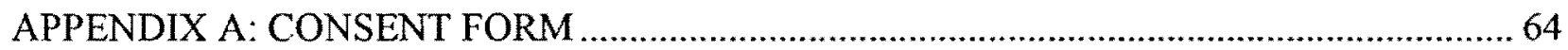

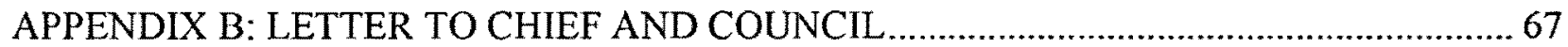

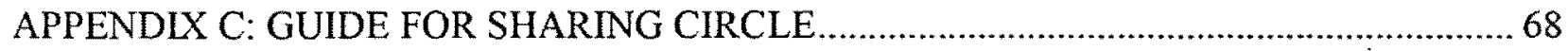

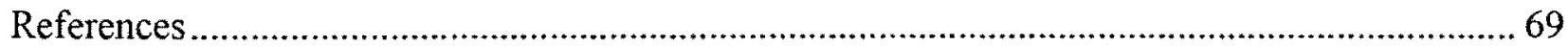

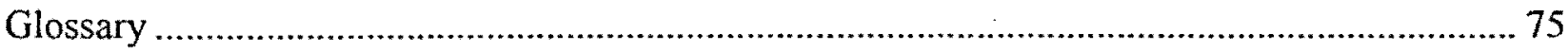




\section{CHAPTER 1: INTRODUCTION}

\section{Identity Development of First Nations Women from Georgina Island}

Indigenous people in Canada have had their ancestral identity and rights removed due to Canadian government legislation. Bill-C31 and the Indian Act (Lawrence, 2003) are the two pieces of Canadian legislation that have had the most negative impact on Indigenous people and the development of their identity. The removal of their rights and identity has impacted their ability to develop a positive sense of self and a feeling of belonging. This research will fill a void in the literature in regards to the role that the Canadian government has played in the identity challenges faced by Indigenous people and give a voice to the First Nations women from Georgina Island who have been affected by the legislation developed by the Canadian government.

The purpose of this study was to gain a greater insight and to share the stories of the women from the Georgina Island First Nations community and how the Indian Act and Bill-C31 have affected their lives. This research will provide data which is relevant for the Georgina Island First Nation, while contributing to the history of the Georgina Island community.

My inspiration to work on this project is a personal one. I feel that it is important to bring awareness to the feelings of those affected by the legislation so that the community can work to support the relationships that people have with their history and further understand that by excluding and enforcing the government's legislation they are participating in assimilation and the cultural genocide of their own people (Wesley-Esquimaux, 2007). I want to strengthen the bond between Indigenous peoples and ensure that future generations to come will be supported in their connection to their community and ancestors. 
I hope that this research opens up the discussion regarding identity in a positive way, so that those who are affected do not feel alone in their struggles. Throughout this process I came to further understand the challenges within families regarding status, such as the division between siblings when brothers were able to pass on their identity while their sisters were not and how this has impacted land ownership, and rights within the community for people having the same blood quantum in the beginning. I would hope that this may support the realization of the importance that a relationship with your community carries in order to help break down barriers within communities so that all people who feel a connection will be honoured and respected for their desire to connect and the communities will reflect their original ways of embracing all people regardless of their nation. I hope to provide an answer to how the Canadian legislation impacts the identity and belonging of First Nations women within their First Nation and in order to gain insight and suggestions to support future generations. 


\section{CHAPTER 2: LITERATURE REVIEW}

\section{The Effects of Legislation on Identity Development}

This literature review looks at how First Nations people in Canada develop cultural identity and how government policy has impacted that development. This literature review will begin by introducing the legislation that governs First Nations people in Canada and then examine how it effects their social interactions leading to strain in their development of identity and belonging.

Prior to the creation of government legislation, Indigenous people did not have to prove their identity, communities were tight knit and ancestry was unchallenged (Weaver, 2001). The need to identify self and prove this identity to government officials began in 1850 when the Province of Canada created Indian reserves which restricted those who were considered Indian on to specific plots of land (Lawrence, 2003). Additionally, in 1867 the Gradual Civilisation Act was created which provided personalized plots of land to men who would give up their identity as Indian and live off the reserve. This sacrifice or enfranchisement as it was called allowed them to own land and have the same rights as other Canadians. The Indian Act of 1876 was created giving Canadian and British government exclusive power to regulate and control the lives of people in Canada who were recognized as Indian by the Canadian government (McGrath \& Stevenson, 1996). Stipulations were created which made new divisions between men and women and were supported through this legislation. Lawrence (2003) writes about the further barriers to Indian status that were created for women in the Indian Act. When a woman married a non-Indian man, she had her Indian status taken away from her and subsequently gained full Canadian citizenship. This removed her ability to live within her community, took away treaty rights and removed her ability to pass on status to her children. Non-Indian women who married 
Indian men gained Indian status. The division between men and women and the need to prove ancestral ties was the start of separation and division between Indigenous people in Canada (Lawrence, 2003). The regulation and control affected life style, traditions and power. It challenged Indigenous people's sense of identity and was very damaging to the future of their nations. By introducing and enforcing a new way of life the ability to continue to value and practice traditions was decreased immensely. People's traditional community roles were no longer passed on through blood line as this was now determined by the government who divided families and created barriers to traditional ways of living. The governmental interference challenged people's ability to hold on to their ways and has removed many people's identity as an Indian person. The ancestral laws supported by the Indian Act have altered how an Indigenous person self-identifies and has created distance and division within communities. On and off reserve division, status and non status separation both create conflict within and weakens the strength of the band or nation, supporting the divide and conquer agenda.

In 1985 Bill C-31 was an amendment to the Indian Act that allowed individuals who had lost their status based on the gender inequity (i.e. grandmother) to regain status. However, Bill C-31 only allowed people to go back two generations to their grandmother, so if they happened to be the third generation this bill did not support their gaining back of status. Daniels (1998) states that over 100,000 Indian people in Canada have regained their status due to this bill. What this bill did was to make amendments to the old Indian Act of 1876 , recognizing men and women equally in issues pertaining to Indian status. When this bill was first introduced people thought it would also create equality between on and off reserve Indians, and increase membership and belonging (Daniels, 1998). What it actually did was to create an even a larger divide. This bill also gave Indian Bands (nations) the ability to control their own membership if 
they chose. Since many of the people being reinstated with Indian status had no connection to their band due to government restrictions on living in their original communities they were not welcomed and granted membership within their ancestral communities (Daniels, 1998). In addition, bringing more people into a community was sometimes not seen as beneficial because of the competition for the limited resources available, some communities were hesitant to allow further membership due to resource restraints.

Bill C-31 included further removal laws. A clause known to many as the third generation clause states that after two consecutive generations of marriages with non-Indian people, the children of the third generation will not have status (Daniels, 1998). This applies to both males and females. Daniels (1998) is concerned that this clause is leading to the disqualification of hundreds of thousands of descendents of today's Status Indians, greatly increasing the population of non status Indians. Denying parents the right to pass on their Indian status to their off spring, denies them the right to pass on their 'Indian' identity, ancestral property, and customs and rights (Daniels, 1998).

Further changes to the Indian Act are currently under way. In the spring of 2010, it was recognized by the Supreme Court of Canada that further changes need to be made to address the inequality between men and women. The changes taking place will further remove the barriers placed on women by the Indian act. Bill C-31 provided status to the women who had it removed and their children, but did not open it up to their grandchildren though the grandchildren of the men continue to have status and band membership. Realizing that an Indian's woman's grandchildren should have the same rights as Indian man's grandchildren, the Court of Appeal ruled in favour of McIvor who challenged the legislation on the grounds that it violated a person's rights set out in the Charter of Rights and Freedoms (Indian and Northern Affairs, 
2010). Parliament was given one year to amend the provisions that in the Indian act that are unconstitutional. These proposed changes will allow these grandchildren to be entitled to the same rights as other grandchildren who are recognized as status Indian through their grandfather.

\section{Impact of Government Regulation}

The language, traditions, ceremonies, knowledge and customs of Canada's Indigenous people were prohibited in Canada until the 1960's (Takeda \& Williams, 2008). Besides having their ways of life prohibited, their children were removed from their families and sent to residential schools so that they could learn not to be 'Indian' and assimilate into the new society. The removal of children has been very destructive to communities who traditionally believed that children were a gift from the Creator and that the purpose of a community was to provide a place of balance which supports the rounded development of the children and their nation.

Without children communities lacked their purpose and traditions were removed leading to the self destructive behavior which is still seen today. Traditionally Indigenous people strived to live with a sense of harmony. They were inspired to balance their spiritual, emotional, physical and mental identities (Garrett \& Herring, 2001). The removal of their ways of living by legislation, the residential school system and child welfare has created challenges in positive identity development (Wesley-Esquimaux, 2007). The children who were taken to residential schools were not permitted to speak their language, practice rituals or respect their traditional ways of life. They were taught that their ways were backward and they developed lack of respect for their own ways. Lack of respect and living separately from their families did not allow children to have the traditions passed on to them as they once were through the generations (De Souza \& Rymarz, 2007). 
Hall (2001) believes that the forced changes in daily living for many Indigenous people lead them to viewing themselves as inferior to the dominant culture. When people view and see themselves being negatively portrayed by society they can suffer emotionally and feel confined to an identity which is demeaning (Weaver, 2001). Identity is a both a personal view and a reflection of how others view you. Negative stereotypes and lower perceptions reduce a person's ability to have pride in themself. It is important for people to see their ethnic community positively portrayed in order to support them in developing a healthy identity allowing them to live a healthy, happy way of life.

Traditionally Indigenous people determined who they were, where they belonged and where they would live (Weaver, 2001). People need to be able to decide how they wish to see themselves and what makes them feel valued and what is meaningful to them. Identity development is motivated by feelings of satisfaction with people tending to lean towards things that make them feel good about themselves and things that are normally meaningful to their lives (Vignoles, Regalia, Manzi, Golledge, \& Scabini, 2006). The Canadian legislation that determines how and where Indigenous people will live, who is recognized as being Indigenous, and the restrictions and exclusions have had very negative consequences for Indigenous communities in Canada. A person's identity or how they choose to identify cannot be assumed by others, including the government. Individuals should have the freedom to decide how they will move forward in self recognition (Morrison \& Bordere, 2001). Indigenous people in Canada have their identity decided for them by the federal government by granting status or refusing status. This impacts where they feel they belong and how they view themselves. Membership within one's community is influenced by the ownership of the status card. Weaver (2001) points out that the pressure to prove identity is not universal for other ethnic groups in Canada. 
Indigenous people in Canada are the only ethnic group whose identity is dictated by the Canadian government. Though other ethnic groups feel identity struggles, the dictation by the government creates challenges which place restrictions and barriers removing choice and freedom in the development of a healthy identity.

Weaver (2001) sees identity development as a lifetime process that every human being goes through. An individual's identity is always changing due to the experiences they have and how they perceive those experiences. The journey of developing a positive identity is one of self awareness. Each individual is an expert on their journey of self knowledge. This process is influenced by everything in a person's life. People play an active role in the development of their identity by consciously deciding on every aspect of their identity when given the choice. The life experiences that a person has will determine how their life unfolds and how they will choose to identify (Keddell, 2007). People generally determine who they will have relationships with and what values and beliefs they will live by. Developing a positive sense of identity is important for people and allows them to be more emotionally and mentally stable (Morrison \& Bordere, 2001).

Gaining a deeper understanding of oneself supports an individual in understanding the circle of life and a growing awareness that nothing is an entity on its own seeing how everything and everyone is connected (Myers, Highlen, Reynolds, Adams, \& Hanley, 1991) This awareness allows for the recognition that we are attracted to an identity that has value for us and this attraction is influenced by our ancestors, community, natural environment, age, race, or social class (Myers et. al., 1991). People gain a deeper understanding of self when they realize how their choices are influenced (Myers et. al., 1991). Understanding that everything is connected 
and that nothing is separate supports a deeper understanding of self and will allow for people to gain an identity which is authentic, providing them stability in their lives.

The process of gaining self awareness is essential to health and happiness. When an individual is identifying with what is right with them internally they will not feel challenged but secure and strong in their life. It is the process of determining what supports you internally that is the process of development. There are two main areas to reflect on when thinking about how an individual develops their vision of self. Their inner self is developed through their actions, while the outer self is determined by others (Myers, et. al., 1991). If they are successful at something, it supports positive identity. All people regardless of their culture or social location will work to create a positive self identity (Vignoles, et. al., 2006). Many things motivate the formation of a positive self identity, such as acceptance from others, positive relationships, seeing self positively mirrored by others, competence and control. People who feel these things are less likely to participate in things that could harm them, have better health leading to an increased life span (Vignoles, et. al., 2006). When we are developing our identity and sense of self we will naturally focus on those things which we are good at and that make us happy. These things generally bring meaning to our lives (Vignoles, et. al., 2006).

The discovery of self and development of identity is influenced by our opportunities and successes and how a person feels others perceive them. We develop and grow through these opportunities and accomplishments by our ability to navigate these experiences. When we feel able and when others perceive us positively it supports us in developing a positive, strong identity. This feeling of positive perception and ability is known as self efficacy. Gecas and Schwalbe (1983) recognize that self efficacy is important to a healthy sense of self. Regardless of how well a person is able to function in comparison to others is not important, what is important 
is how well they perceive they are doing. Surrounding yourself with people who see you positively and withdrawing from that which makes you feel less so will help to strengthen your self esteem and overcome the challenges and obstacles (Phinney, 2008). Many minority people have grown up seeing themselves negatively portrayed in society. This challenges their ability to see self in a positive light (Phinney, 2008). It takes great effort to overcome feelings of inferiority when the society and media in which you find yourself living constantly confirms the stereotype which you are trying to overcome.

According to Eric Erikson, in order to develop your identity you must go through a period of exploration. This exploration can be impacted by noticed individual differences, racism, or having one's individual identity questioned (Germain, 2004; Miehls, 2001). Individuals from the majority culture may be less able to explain where they are coming from since their identity is rarely questioned. They may not see their differences as often as minority people because they are able to see themselves constantly reflected within society. This lack of questioning may limit the amount of internal dialogue they go through in developing their identity. Being a majority reduces the individual exploration and journey of individual self knowledge and decreases their chances of reaching their own authentic identity which reflects their individual values and beliefs but simply is reflective of those around them with whom they feel connected. Minority people through their exploration due to challenge have the opportunity to develop an identity which honours their distinctiveness.

\section{Community}

For Indigenous people, the development of positive identity is greatly influenced by community and belonging as this is part of many Indigenous peoples belief system (Public Health Agency of Canada, 2010). Many Indigenous individuals find themselves caught between 
two worlds. They feel a connection to their ancestors, which is either recognized or not by the government, their community and their peers. They either live in their First Nation communities or outside due to opportunity or inability to live within due to membership. This creates challenges in connecting with their ways (Weaver, 2001). For many Indigenous people, a community and its people validate who they are, and provide a place of belonging. Many Indigenous people identify themselves by their 'reserve' or community (Weaver, 2001). Dislocation from community can negatively affect belonging and identity. Many people who have grown up outside of their communities feel a sense of distance and loss of their ethnic identity (De Souza \& Rymarz, 2007). This is due to the fact that much of our own traditional knowledge is dependent on the community we are connected to and in order to learn your traditions you need a connection to the community (Ball \& Simpkins, 2004). With the absence of a community there becomes a division and sense of 'us and them', making those who don't or are unable to live within the community to feel as if they do not belong anywhere (De Souza \& Rymarz, 2007). Not only do Indigenous people find themselves challenged by legislation but they are challenged within their own communities. Weaver (2001) sees it as problematic for people to have identity determined for them, such as being identified by the legislation as status Indian but then not to receive that validation from the community or group. Rejection by those whom you feel connected to can add to the challenges faced for Indigenous people when developing a sense of who they are. It makes it difficult to develop a sense of belonging and acceptance of self (Deters, 1997) and can lead to a sense of abandonment and frustration.

Due to years of colonization many Indigenous people have taken it upon themselves to determine who should belong and who should not. Weaver (2001) believes that "identity can only be confirmed by those who share that identity" (p.245). First Nations communities need to 
recognize the negative impact that these barriers create for their children and families and that in order to the community to be strong and healthy inclusion, instead of exclusion, needs to take place.

\section{Power}

When people feel in control of their lives they are able to live a happier, healthier life. When people are not given choice they lose their power and their opportunities become limited (Morrison \& Bordere, 2001). People who feel like they have no control begin to establish learned helplessness (Gecas \& Schwalbe, 1983). Many Indigenous people in Canada feel a loss of control over who they are, their way of life and their identity due to having these things determined and dictated to them at birth. Though a piece of First Nations peoples' identity is decided for them at birth by the Canadian government they still have the power to decide on the other areas influencing their identity.

When Indigenous people see themselves negatively portrayed within the dominant society this environment does not provide a place for Indigenous people to decide for themselves what feels right. They may be 'afraid' to be true to themselves for fear of more rejection from the society they find themselves in and feel that what they are drawn to and find meaningful is 'wrong'. This fear leads to a halt in decision making for fear of making the wrong choice. This fear of feeling more rejection creates lower self esteem and a feeling of challenge in the development of a positive self identity. When a person believes that how they wish to identify will cause them harm, it challenges their ability to move forward and overcome feelings of shame and embarrassment due to their belief of being less than others (Phinney, 2008). People who have lower levels of power are more dependent on the opinions of others for their development of self-esteem (Gecas \& Schwalbe, 1983). People are sometimes challenged more 
than others in their opportunity to have success. For Indigenous people the skills which are valued in their communities may make them feel strong and positive, the challenge however is that these skills are usually not valued within the dominant society, leading people to feel lacking when they are not within their culture and reducing their opportunity for to feel successful outside of their community. If an individual is surrounded by a society which is structured by beliefs and values which differ from their own they may be unable to find success within the environment (Gecas \& Schwalbe, 1983). In order to step out of this circle of rejection, people need to surround themselves with people who will see their choices as positive so they will see self in a better light.

\section{Conclusion}

In conducting this literature review I noticed some gaps in the literature. Articles and government websites which reflected on the legislation affecting 'Indian' people in Canada very rarely brought to light the problems with identity development. There was plenty of research conducted on identity development and ethnic identity development but very few articles looked at the effects that legislation had on identity development with First Nations people in Canada. There is limited information regarding Bill-C31 and the Indian Act. The articles mainly look at history with a lot of focus on addiction, crime, gender, poverty and treaty obligations. I found that there is a need for research on how history and legislation affects identity which may be the answer to many of the articles that focus on the deficits within Indigenous communities.

Lavallee (2009) stresses the need for more literature that explains and develops an understanding of how to conduct research within Indigenous communities that is respectful and of benefit to the community. Research needs to recognize and respect an Indigenous worldview and not view people from a deficit perspective. In conducting this literature review I found that much of the 
research on identity of Indigenous peoples was not respectful or beneficial to Indigenous peoples because it focused on the deficits and ignored something as fundamental as the impact of the Indian Act on identity development. I recognized there is an essential need for research by Indigenous people about Indigenous people in Canada. I now further understand the impact that legislation has had over Indigenous people in Canada and how that has impacted their identity and relationships within communities. I hope to combine the areas of legislation and identity to bring awareness to First Nations communities and encourage them to recognize the negative impact that legislation is continuing to have and that communities are continuing to enforce colonization by rejecting those with ancestral ties to communities. Can communities open their arms and overcome their histories in order to embrace everyone who has a connection and allow them to make their own choice in identity? Can policy, even within communities be changed in order to support the positive growth of generations of Indigenous people?

For the purpose of this paper I did not include research on the negative impact that the residential schools and current education system in Canada has had on Indigenous identity development in Canada though it has played a large role in the problems that people are facing today. I chose to focus on our own identity development, our own communities and what we can do as Nations to support our own people while they are living within dual societies. The hope is that this research will one day help to break down barriers within communities so that all people who feel a connection will be honored and respected for their desire to reach out to their ancestors. I hope to support policy which will encourage positive identity formation and belonging within Indigenous communities that reflect our original ways of embracing people.

I have chosen to focus on the feelings of the women from the Georgina Island First Nation, and how the legislation has impacted their lives in order to give their stories a voice and 
to address the lack of literature exploring the impact that legislation has had on Indigenous people's identity development. My reason for choosing women is also due to their role within Indigenous communities. Women are the caregivers, they have a strong voice and will lead change. The women provided a voice for the children who are seen as a gift from the creator. By listening to the voices of our women we can reflect on the historical impact of legislation and grasp an understanding on how it has affected parenting and childhood. 


\section{CHAPTER 3: METHODS}

\section{Theoretical Frameworks}

An Indigenous and a critical theoretical framework were used to support this research. It is important that the researcher as an Indigenous person doing research within a First Nations community use a framework that respects indigenous knowledge (Smith, 2002). The researcher being from both worlds sees the value and strength that a mixed perspective can have when working together. These two frameworks support this research and guide it so that the outcome of the work is respectful and meaningful to the community and the researcher.

The Indigenous theoretical framework is respectful of and honours the values and beliefs of indigenous peoples. According to Morrisette, McKenzie and Morrisette (1993) "this theory is grounded in four main principles: the recognition of a distinct Aboriginal world view, the development of Aboriginal consciousness about the impact of colonization, cultural knowledge and traditions as an active component of retaining Aboriginal identity and collective consciousness and empowerment as a method of practice" (pp. 91-92). It is grounded in the understanding that knowledge is received from experiences, understandings, worldviews, values and beliefs and that there is distinctness between Indigenous people and their customs and traditions (Lavallee, 2007). The researcher worked from a place which recognized that all things are connected, that traditions will support positive future growth and that knowledge should be obtained in a way that recognizes and supports the empowerment of Indigenous people by embracing their ways.

A critical theoretical framework acknowledges the restraints placed on people while supporting people in overcoming challenges and creating change (MacDonald, Hill, Harvey, 2000). Research from a critical theoretical lens works to improve a situation through gaining an 
understanding about what is at the root of the problem (Wilson, 2001), by allowing the researcher to recap the history of a people, hear their stories and embrace their knowledge in order to move forward and support positive change. The researcher felt that the combination of these frameworks honours indigenous traditions while supporting positive change through recognition of the past, the present and wishes for the future. The researcher believes that change begins by bringing awareness to the people, and that the power to change is within the individual. Together an indigenous and a critical theoretical framework allows the researcher to be true to herself, her community, and her ancestors while recognizing that the ability to overcome identity obstacles lay within the individuals and their community.

Keeping with the community traditions and an indigenous way of conducting research, an Elder helped to guide the research. An Elder from the community was approached for guidance and support throughout the research process (Lavallee, 2007). In addition participants played a key role throughout the research project. They played a key role in determining site for the sharing circles, and how data will be analyzed. Upon completion of the research paper the Elder will once again be approached in order to determine the best way to share the information at the end with the community. Sharing the information at the end is important and necessary in order to meet cultural protocols and expectations (Kenny, 2004). In keeping with the method of this research, the researcher recognizes that this project is grounded in her identity, her connection to her community and the issue being explored and she will be forever obligated to her community.

\section{Research Design}

An indigenous and critical theoretical framework is being used for this research project. Indigenous theoretical frameworks value the role of participants by recognizing the need for them to be fully involved in the research design, data collection, analysis, and sharing. The need 
to use an indigenous framework is necessary when working with First Nations people. This necessity is due to the history of research within First Nations communities. Historically, research in these communities was very disrespectful and had devastating consequences. It was done with the intention of deciding what was best for Indigenous people, based on the goals of assimilation and cultural genocide (Smith, 2002; Wesley-Esquimaux, 2007). Research on Indigenous people has been devastating to their communities and people. Researchers came into communities made observations based on their worldview and perceptions and reported back without any input from community members regarding their needs or wishes (Schnarch, 2004). Research was aimed at filling the needs of the researcher with little or no regard for the people being researched. Articles were written, changes were made based on the perceptions of outsiders who lacked an understanding of the Indigenous worldview, leading them to see Indigenous people as inferior and lacking in social structure and ability. A critical theoretical framework supports people in overcoming challenges and creating change while recognizing the restraints that they may be under (MacDonald, et. al., 2000). Together the combination of these two frameworks will allow the researcher to support the participants and write from a place of respect and understanding.

In Canada, the need for change and guidelines regarding research in Indigenous communities has been recognized by the development of the Ownership, Control, Access and Possession principles also known as the OCAP principles (Schnarch, 2004), the Tri-council Policy statement (2009), and the Canadian Institutes of Health Research (CIHR) Guidelines for Health Research involving Aboriginal People. The research community is beginning to listen to the voice of the Indigenous peoples, when they say they will determine what is best for them, how research will be conducted and how the information gained will be shared while playing a 
key role throughout the whole process. Now, Indigenous communities are also developing their own research ethical protocols, such as the Manitoulin Anishinabek Research Review Committee, the First Nations Environment Health Innovation Network and the Kwanlin Dun First Nation to name a few. Community created ethical guidelines ensures that the community's unique needs and ways are being respected and met. When research is based on the community's needs, the community will reap the rewards ensuring that the research is meaningful to the community, in order to allow for growth and positive outcomes.

This qualitative research supported the Indigenous traditions of the First Nations community where the research was conducted. This process supported the researcher to gain indepth information that honours the individual's experiences by allowing them to be in control of the research, while respecting their ways of sharing their knowledge within a group or personal setting which is respectful and safe. The sharing circle was used for group sharing, it differs from a focus groups in that it recognizes that the spirits of our ancestors and the Creator are present, and that energy is created by the circle of people. They are used for healing. The project was conducted in a way that incorporates the values and beliefs of this community. The participants had the power to decide on how they would share their stories and in what way they felt it was most meaningful. It is based on what the community views as important for their future by being conducted in a way that supports Wilson (2008) three R's for research within an Indigenous community, respect, reciprocity and relationality. The researcher's lifetime relationship with this community and the women in it guided the questions that were asked in this project. 


\section{Participants and Sampling}

The researcher purposefully selected the participants that were included in this project. Purposefully selected participants are chosen for they are best able to support the researcher in understanding their question and addressing the problem (Creswell, 2009). The participants were chosen based on the impact that the legislation has had on their lives. I chose women who I know had their status removed, whose children are now Bill-C31 status Indians and whose grandchildren are impacted. I purposefully selected the participants so that my research can share their stories and bring awareness to the impact that legislation has on their identity development. The researcher chose to work with women because the legislation has had a greater impact on their lives and the researcher believes that they will be the ones to lead positive social change. Within Indigenous communities it has been said that when the women heals, the family and nation will follow.

The participants were selected based on one or all of the following criteria: women who married a non-Indian person, women whose children have been affected by the legislation and Bill-C31, and those women whose grandchildren are affected by the legislation and Bill. The women were all from Georgina Island or have ancestral ties to the community. The researcher approached the participants and asked them if they would be interested in participating in the research project. The woman were given a consent form and the researcher discussed the research question, the questions that will be asked, the process, and the risks and benefits to the community and the individual and the participant's ability to withdraw at any time or to feel no obligation to participate due to the relationship with the researcher. An ethical problem with subject recruitment could be that the researcher knows the community members personally and professionally. To address this the researcher made it very clear that they are under no 
obligation to participate and that if they choose not to it would not affect their personal or professional relationships in the future.

\section{Site of the Research}

The researcher chose to do her research on Georgina Island First Nation. This site was purposefully selected based on the researcher and her research question (Creswell, 2009). Within this community there have been many families who have been impacted by this legislation. The researcher is a First Nations person from this community. She feels it is appropriate to use her education to bring her peoples voice to paper. This community is close to urban areas. This information gathered in this project may provide awareness to other First Nations communities who have had the same experiences, allowing their women and families to recognize themselves under a positive productive lens, which is respectful and hopeful for the future. The sites within the First Nations community were determined by the participants. A letter to the Chief and Council of this First Nations community was drafted and signed by them prior to seeking ethics approval from the university to ensure that it was approved for this researcher to conduct this study within this community. The seeking of approval from Chief and Council is necessary when working with a First Nations community. See Appendix B for the signed letter created for approval of conducting research in this community.

\section{Data Collection}

The data was collected through a sharing circle and personal interviews. Sharing circles are similar to focus groups but not the same. The sharing circle is known to the First Nation participants in this study. Historically sharing circles were used as a way of healing (Lavallee, 2007; Stevenson, 1999) within First Nations communities. The sharing circle differs from focus groups in that it recognizes that the spirits of our ancestors and the Creator are present, that 
energy is created by the circle of people, and the circle is non-judgemental, helpful and supportive (Nabigon, Hagey, Webster, \& McKay, 1999).

The sharing circle began with a smudging ceremony. The smudging ceremony rids the circle and its people of any negativity they may be feeling or which is surrounding them. A feather was held by the participants while they were sharing and then passed to the next participant. The feather was passed clockwise around the circle of people. This is the way in an Ojibway community. When people didn't wish to share they just pass the feather on to the next participant. Everyone had a chance to speak and they were not interrupted. The participants went around the circle as many times as they felt necessary. The researcher provided an environment where the participants felt free to express their opinions openly and honestly. During the sharing circle, the researcher engaged in the process of sharing (Lavallee, 2007). At the end of each circle a smudging ceremony was conducted with the goal of removing any unpleasant thoughts that the sharing may have brought up in the hopes of everyone leaving in a good internal space. Appendix $\mathrm{C}$ provides the outline that the researcher used for her sharing circles. Observations and notes were made immediately following the circle. Participants were also offered the opportunity to engage in one on one interviews when they were not comfortable sharing within a larger group.

One sharing circle and five personal interviews were conducted. Participants were between the ages $30-49$ years of age and $50+$ years of age. Personal interviews were conducted with all three women from the $50+$ category. Each one chose this type of sharing as it met their individual needs. A sharing circle was conducted with three women in the $30+$ group (researcher was one of three). Individual interviews were chosen by the two other women in this group due to outside time constraints and personal choice. 


\section{Research Questions}

The participants were asked the following research questions: "Growing up did the Indian Act impact how you viewed yourself as an Anishnaabe woman?" "If so, can you describe how you viewed yourself?" "Did it influence your relationship with your community?" "If so, can you describe how?" "Have you ever felt restricted and controlled due to the legislation?" (Probes-getting married or who to marry, having children etc.). "Do you believe that children will and should have a relationship with their community even once their status ends?" The limitations of these questions are that times have changed since many of these women made decisions based on these areas of questioning. Their outlook may have changed, their live view may have changed and they will be in a different space in their lives. The researcher believes that the answers would have been different if they had been asked a few generations ago.

\section{Data Analysis}

The tapes and notes from the interviews were transcribed, and organized for analysis. This analysis involved reading through the data numerous times in order to gain a deeper understanding of the information which came out in process (Creswell, 2009). At this point the researcher interpreted the themes and reflected on the findings which allowed them to group similar topics together and begin bringing data together to be further analyzed and interpreted. After further analysis the data was coded in order to determine the themes and descriptions of information which came out of the interview. The researcher used emerging codes in this analysis (Creswell, 2009). This process was influenced by the reflective notes which the researcher kept during the process.

At this point the researcher met with the participants individually to share the themes that emerged. This method of member checking helps ensure the data and the analysis is accurate and 
reflective of the participants of the study (Punch, 2006). Having participants share in the analysis supports the researcher's choice to use an indigenous framework by having them play a key role in this process. When using this framework, it is important for the researcher to recognize how they are accountable to the participants and that their input is very important to the process and meaning of the work being completed. The researcher is accountable to the community, by seeking their input at this time the researcher feels that it will ensure that the research reflects the message that the participants want shared. This type of analysis allows the researcher to fill their obligation to the community, the participants and self while supporting, building and sustaining respectful relationships (Wilson, 2008). My findings were shared with my supervisor and an Elder for further guidance in the sharing of this information. 


\section{CHAPTER 4: DATA RESULTS}

The analysis of the data revealed a variety of themes; the themes are all connected as all things are. The themes that emerged were "Affects of the Indian Act", "The influence of Bill C31", "With or without status", "Choice: Life partners and procreation", "Keeping the relationship alive", "Struggles inside and out", "Loss of culture", and "Our wish for future generations". This study found that all the women interviewed have been affected by the Canadian government's legislation: Indian Act and Bill C-31. Each woman has wishes for our future generations and has made recommendations for how they would like to see our children in the future connect to the community and what role the legislation should play in our lives.

\section{Participant Profiles}

Each participant was given the opportunity to choose a pseudonym in order to keep their identity confidential. There were three women in the $50+$ category. One chose the name Frances and the other two simply wanted to be called Elder. Therefore, when sharing their ideas in this paper 'Elder' will be used. There were five women in the $30+$ category. They selected the names River, Morning Star, Thunder, Autumn and Wind. All of the women participating in this study have lived both in and out of their First Nations community, but now have a strong connection to their First Nation. They have been affected by the Indian Act and Bill C-31 legislation and their future generations are or will be affected by the governmental constraints on who belongs. These women have been educated inside and outside of their community and feel a strong sense of pride when sharing information about their culture.

\section{Affects of the Indian Act}

All the participants indicated that the Indian Act had a profound effect on their identity growing up. These effects were felt from an early age and are still being felt by all participants. 
Though changes have been made to the original Indian Act it still negatively influences the lives of these women. The Indian Act is a piece of paper which controls the lives of Indigenous people in Canada. "It told you and instructed you on how to live." (Elder) It was brought up by an Elder in her interview that no other race in Canada is governed or controlled by the Canadian government like her people. She said, "It is terrible to have your life guided by an Act. There is no other thing like it." When participants shared their thoughts and feelings about the legislation and its effects on their lives, the Indian act was described by these quotes, "It defines who's an Indian and whose not."(Frances) "It's a piece of paper that says if you belong or not."(Morning Star) "It was demeaning, especially for women, it made you a non-entity." (Elder) "It controls your sense of belonging." (Thunder) "If the Indian act says you don't belong, then you question whether you really do." (River) Each of these quotes provides insight into the amount of control over identity that the Indian Act had on these women.

Each woman in the $50+$ group was fully aware that their lives were decided by an outsider and that those people had control over their families. They each shared that they were always aware of the control that the government had over their families. "We knew when we were young that the Indian agent decided if we stayed with our family." (Elder) The women in the 30-49 group, appeared to be unaware of how governed they were by the Indian Act while they were growing up. In their teens they became aware that the legislation was in fact influencing many areas of their lives. Prior to this recognition each one thought that it was their community and family that determined if they were allowed to live in their community, or whether they were an 'Indian' or not.

The Indian Act impacted me, but I wasn't aware that it was the Indian Act. It is not something that is in your face every day, you don't see it. It is very subtle how it is being done. (River) 
As stated by River, the Indian Act was very influential to identity. "It has had a profound effect on my identity but I had no awareness that it is what was causing me to struggle with my identity." (River) This struggle and influence is recognized by the group as a tool to weaken their unity and strength as a Nation. It is looked at as a tool to divide and conquer Indigenous people. A concern that was felt by the participants was the fact that many members are so submersed in the way that the legislation determines membership that they are unable to see how they are implementing the governmental structure by ostracizing their own people whom they have ancestral connections to. "The Indian act impacted my relationship with my community, it created a divide. It divided everyone and still does." (Frances) For many the wish for the end of government control was shared. "I hope the Indian Act ends that those walls and misconceptions and divide end." (Autumn)

The legislation created over us by the Canadian government is structured and designed to divide and conquer us. That's what is being done, only when we reject their system and go back to our way will we be able to support our future generations. (River)

This feeling of judgement and approval was felt by the group. If they did not feel judged for status, they felt judged in their behaviour. Their behaviour determined whether they would be removed from their homes by government officials. An Elder explained she always was afraid that if she didn't act a certain way the Indian agent would take her away. She shared that this was a common feeling, it was gut wrenching and she said no word in English would explain how the community felt about this judgement.

The dictation of identity and acceptance influences a person's feeling about self. Frances explained how she felt judged and in need of approval. She said when asked about the legislation,

It makes you doubt yourself and your feelings cause you don't have government approval. Kind of like how I imagine they judge beef...grade A, it's like you're not grade A, your 
down there in with the dog food you know, more like they look at me as dog food. (Frances)

There was shared concern over the differences between men and women in the Indian Act and how it continues even though Bill C-31 was created in order to reduce the inequality between men and women. "It has different rules for men and women. It was one sided and unfair." (Elder) "If my brother married a non-native woman before 1985 then she became an Indian. When I married a non-native man prior to $1985 \mathrm{I}$ lost my status, my land holding, I lost everything." (Elder) "It made me a visitor in my own community." (Elder) This inequality between men and women is further demonstrated when the women shared their thoughts about Bill C-31 and the impact it has had on their lives.

\section{The Influence of Bill C-31}

Bill C-31 has impacted the participants and will continue to impact their future generations. When the women explained how the legislation impacted them they shared what it felt like to have their status removed due to marriage, what this removal meant to them and what it felt like to have their status returned.

When status was removed many of our women moved to a neighbourhood in the local town off the reserve which provided housing within a local subdivision. This Indigenous neighbourhood within the subdivision was known as 'Indian Housing'. This Rural and Native housing development which provided low income housing for Non-status and Métis peoples was provided by Canadian Mortgage and Housing Commission (CMHC)(Canadian Mortgage and Housing Commission, 2010). This housing allowed the 'island' women to live close to their family, in a neighbourhood just outside of their First Nations community. One of the women felt that "the white community didn't want us in their neighbourhood, we weren't well liked and we didn't fit in." (River) One of the other women who lived in the subdivision did not feel the same 
disapproval. "I suppose I didn't think about what others in the community thought about us. I was fairly young and felt the same as all the kids running around." (Thunder)

Once Bill C-31 was passed many families began to move home after having been away for a long time. "It was so good to come back home" stated on Elder. All women from the 50+ group felt that they could not voice their opinion or concern for a while upon return, because many of the people who had never had to leave felt that they would come back and try to tell them how to live or want them to change. After many years of living in the community they now feel that they have the right to voice their opinions again. An Elder described it as, "You grow up in a community, have it taken from you, then have your right to it returned, but then have to fight to gain access and membership back within it." Having status provided benefits for these women. They were able to move home and they had access to programming for themselves and their children. Thunder shared, "Having status made it easier in the community. Without status you felt restricted, you felt like you have no opinion."

Concern was shared by one of the Elders over how status was returned. She shared,

\begin{abstract}
"When I got my status back, I received a letter from the government. It was very demeaning. Those letters were horrible. I think we all got them... The letter said, 'Welcome to your reserve. You are now a full status Indian.' I thought to myself, I have always been a full blooded Indian and who are you to take it upon yourself to think you are giving me back my identity."
\end{abstract}

Though the women were happy to have their status returned they continue to be concerned by the continuation of inequality between men and women in regards to status and band membership. Currently, the grandchildren of the men who are $1 / 4$ Indian have status while the grandchildren of the women who had their status returned who are also $1 / 4$ Indian do not have status. The women's Indian status was only returned to them and their children as per the bill. All the participants mentioned the "McIvor case" (Indian and Northern Affairs Canada, [INAC], 
2009) in which the appeal court of Canada ruled in favour of recognizing the inequality between the grandchildren of the men and women who married prior to 1985 . All the women were aware that the government has been instructed by the court of appeal, to amend the Indian Act in respect to this discrimination between men and women. The hope that all these women share is that the government will in fact comply with this order and the children entitled to this status will be granted it.

Another struggle that was felt by all participants was the issue of land ownership and the passing of ancestral property on to your kin. Currently you need to be status to own land within a First Nations community. People who have a community connection but do not have status are able to lease the land from a member but that leaves them at the mercy another. Connection to land is important to Indigenous people. It is important for the participants to be able to leave their land to their children and grandchildren without having the government control their ability to keep land in their community. This ability to lease land is the same for any other person regardless of whom they are or their connection to the community. It recognizes those that have a connection as being no different than those who have never been in the community and do not know anyone or the history. This concern was voice by all participants regardless of age or status.

\section{With or Without Status}

Status was looked at as creating division within a family and community. This division depends on a person's life partner choices or those of their ancestors. "It may be a good thing when status runs out and we are no longer divided by it. We will then be close and count on one another regardless of it."(Autumn) She also stated: 
It's divided, you are or you're not, you have it or you don't. It makes you feel like you aren't enough for even your own people."

Equal access to resources and support was meaningful to participants who had their status returned or given. It made them feel equal to others and gave them a feeling of fairness. The trouble with the Federal Government determining this fact was that sometimes a community member marries someone who had children prior to their marriage. These children have no ancestral ties or connection to the community but are granted status and membership due to marriage. Children who are raised having a relationship with the community and have ancestral ties do not always have the same benefits due to the government restrictions and influence. These benefits can be community support when having to work with agencies such as the police, school boards, or family support service agencies. As one woman put it "it pisses me off to serve children who have no connection to the community when I wouldn't be able to support my own children in the same case." (River)

One of the participants was very sarcastic about the status card, even though both she and her child have status. "Oh, you couldn't possibly be an Indian unless the government gave you one of their paper cards and told you you were. Remember they are the ones who know who belongs in our community not us. What do we know?" (Autumn)

River recalls feeling pressure to justify her status depending on the situation. "When outside my community in another First Nations community I sometimes feel that I have to tell people I am status, I guess 'cause I may not look the part but want them to know that I belong". "We put too much value on status and whether someone has it or not." (Autumn) Wind also feels the pressure that status or appearance make when she thinks about taking her children to 
powwows or other cultural events because they do not look the part though they have the piece of paper.

I sometimes don't take my children places because I don't want people making them feel as if they don't belong. I don't want to feel like I have to tell people they belong and that they are status. It's wrong. I don't want them spending time with people who are like that, we all look different but everyone should be made to feel welcome, I feel it is rude and not the way I want my children to be so we are better off not attending. (Wind)

Being unsure of one's self and not knowing where you belonged was mentioned by many participants. "Before getting my status back, I thought I was too white to be an Indian, but I also knew I was too Indian to be white. I didn't really fit anywhere.... It leaves you wondering where you stand in either society, it makes you question yourself." (River) "When you are older you realize, I am status cause of this, or I am not status cause of this. I have this much blood, or I don't have this much blood. You are aware if you do this (marry out) status will run out for your children." (Autumn) The internal questioning appeared to affect all the participants.

The participants recognized that having status gave women more confidence in their communities. For those who had their status removed and then returned they did not feel that they had a voice without status and once they had it returned after a length of time they felt that they had a right to voice their opinion. "It took time for me to be able to feel I could voice my opinion." (Elder) For the women who had never had status but then gained it, it also gave them confidence in their community and made them feel like they had as much right as anyone else. "There was both Native and Non-native people in the community. I thought I have just as much right to be here as they do." (Elder) Upon gaining status people felt entitled to the same jobs, programming and opportunities as all others. Thunder shared that when she gained status she was able to work a summer job in the community which helped to build stronger relationships with other community members. Though everyone in the study felt that being Native had 
nothing to do with having a card or piece of paper they recognized that it was very influential in giving you rights and a voice within the community. The power that it gave was not looked at as a good thing but recognized as being the way it is. As Wind states, "It isn't right that the government tells us who is included but it is how it is and it is hard to change because of the communities need for government funding in order to support its members."

\section{Choice: Life Partners and Procreation}

All participants recognized the influence that the legislation could have on their future generations when they were looking to choose a life partner or procreate. They all recognized how you really couldn't help who you fell in love with, but that it did affect their future and the future of their children. For the women in the 50+ category, each married for love and though they were concerned about losing their identity, marrying someone that they loved was more important. "It was a big decision because you knew you were going to lose your status, but I guess it didn't seem as important as marrying someone whom you loved." (Elder) For the woman in the $30+$ category it varied, four of the women had children with men they had fallen for without feeling guided by the Act or by their family. Two of these women questioned their decision internally and still wonder if they made the right decision though they still claim to love their partners and the children that they have with them.

The future pressures of status impact their feelings of loyalty. As Wind ponders her decision she says "I wish I had didn't have to think about my grandbabies not having status, I hope they feel a connection to my family and people don't make them feel less connected due to my choices." River also shared, "I asked a friend of mine if he would claim to be the father of my children to fill the government requirements, but in the end it was more important for my future ancestors to know where they came from rather than meeting governmental standards." 
Autumn stated "My father always told me he would prefer me to be with a Nishnaab but you will love who you love". She was dead set on having children with an Anishnaabe man, and having children with $3 / 4$ blood. As she looks back she says, "I would like to think that it didn't play a part in my choice but it did." (Autumn)

For all these women the choice for their children will vary. The children whose Indian status ends with them are being made aware of the effects of their choices and that it would be good if they married an Anishnaabe person if they find one they love. The women with children whose status ends all recognized that the children of today will be carrying a larger burden than past generations, due to the finality of the impact that their choice will have. Thunder and Morning Star were saddened by the burden which they feel they have passed on to their children, as were the other women who fell silence when they began to ponder the future of all our children.

\section{Keeping the Relationships Alive}

All participants indicated that it was important for all future generations to have a connection to the community and feel a sense of belonging. Participants recognized that families played a large role in this connection. In First Nations communities family is looked at as more than your nuclear family. Family does include your immediate kin, but also includes Grannies, Grandpa's, aunties, uncles, cousins, and those who are family by choice which may include neighbours or members from other communities.

The question whether participants believed that children will and should have a relationship with their community even once their status ends got a strong reaction from all participants who thought that all children have a right to their family. The reaction was one of shock for the majority of participants. "Of course. Why? Don't you think they should?" was 
asked of me by an Elder. As a researcher and community member I explained that I was really looking for a strong response, and that I had hoped that this was the answer and reaction that I would get. Because I see a different thing happening. I see people who withdraw from the community due to feelings of not belonging, but my hope is that they will stay connected and it will not matter to them or anyone else.

Participants felt that the interactions and relationships that people have with one another are what make a community strong. In order for people to continue to have a strong relationship it is important for them to continue to interact and participate with their community. Not everyone will want to stay connected to the community but everyone who keeps the connection alive should be honoured and feel a sense of belonging. "Future generations should always feel they can come back, that they are always welcome. This is their home, no matter where they travel in this world they need to know that this is their community. You can always come back." (Autumn)

River was concerned with the role that status plays in regard to relationships. She said, "A relationship with your community can't just end. It is like asking a child to end their relationship with their family, they just can't." The exclusion that children and others without status feel by not being able to own their ancestral land, or participate in programming reduces their connection and decreases their relationship with their community, reducing the community's strength. "Our children need our community and they need our support and guidance, community is all you have." (Autumn)

The hope voiced by the participants was that there would always be a strong relationship with their community and that the community would be strong. Being a small community was looked at as an asset, it was looked at as having more unity and the ability to come together and 
support one another. The hope from the majority was that there would always be people who made others feel welcome, that they would know the family connections and would honour these connections by making people feel like they belong, "This is their home no matter what the government says." (Autumn)

Future generations were looked at as an asset, "They will be the ones to come and give something back to the community. They will be educated. They will be doctors, nurses, teachers

or whatever." (Elder) Community was recognized as what matters the most, "They are your family. They are what is important, not government legislation." (Frances)

Future generations need to know how people are connected so that they will understand their connections to one another in order to further support their loyalty and unity. One of the participants felt that we should take our lead from our children who "embrace all and see the good in everyone."

One of the Elder's believes that it is the people and families within a community that make it strong and that it is up to parents and family to be accepting of everyone and honour our ancestral connections, and to build children up so that they will be proud of themselves and their community. "Regardless of what the government or the band office says they are still from that community, their parents, grandparents, aunties, cousins are still from that community." (River)

\section{Struggles Inside \& Out}

Struggles to belong and be accepted were felt by all participants at some time throughout their lives. It was recognized that many people have taken it upon themselves to ensure that the government restrictions are enforced within communities. This enforcement of the legislation creates division and builds walls within communities. Participants were very perplexed by their own 'traditional' people ensuring that government mandate and approval were enforced, though 
they recognized that those judging and discriminating may not be aware that they are in fact being this way.

You have people who try to make you feel that you are less Indian than them. Even though I am dark skinned, dark haired, I still had people who could make me feel white as snow. This is a big issue, having your own people say you're not Indian enough. (Autumn)

Each participant recognized that there were struggles within the communities regarding blood and status and the influence that it had on their identity, but then they also shared that they felt it outside their community. Thus, prejudice was felt by all participants either inside or outside of the community. "I was too white for my community but too Indian outside my community. There was no getting away from the judgement. You were either too much or not enough for any group" (Wind). This group of women struggled with understanding why people within their own group would try to inflict the same pain that was inflicted on them and their families in the past.

\section{Loss of Culture}

Each participant felt that we have lost our way and need to begin embracing it and turn our focus away from 'their' way to our way. They recognized that we cannot go back but that we can create a new future based on our worldview.

There was a feeling that everyone is trying to grasp on to what is available and how scary it is to think that we have lost our way. One mother was concerned about feeling inadequate when her daughter is old enough to want to know who she is. With tears in her eyes and sadness in her voice she shared, "I feel guilty that I will not be able to answer all her questions about her culture because I don't know." (Autumn) The Elders in the study felt that it is important for everyone to seek out Elders and others who know about our old ways, so that we can support our children and youth in knowing who they are and feeling proud of their Anishnaabe culture. The 
participants recognized that the legislation was to blame for the lack of traditional teachings within their community. "We don't know cause it was beat out of us for generations. Our ancestors were oppressed so they were unable to pass on their teachings." (Autumn) "My dad knew the teachings but he didn't share with us. He didn't want us to go through what he went through. He felt it would bring us pain, but now we are struggling to get it back and they are gone and can't teach us." (Autumn) Wind responded, "Yeah, my dad felt the same way, he didn't want us to be hurt". Fear of continued discrimination and retaliation by government officials and mainstream society was a major factor in the lack of transmission of knowledge. This lack of cultural knowledge was looked at as loss and is recognized as causing many in our community to not know where they come from and who they are. People are unsure what is expected of them or how they are to live the Anishnaabe way. Autumn tearfully expressed, "It is sad. People feel it, they know deep down. They are just unsure how to be. We are wondering around lost, it's an awful feeling. I am still lost."

This great loss and sadness was recognized by the participants. One Elder expressed no longer wanting future generations to feel hatred and anger regarding the loss that our people have been challenged by. She recognized that they would always feel sadness, hurt and loss, but she could not see the value in wasting ourselves in a place of anger and hatred and she hoped that future generations could continue to move forward and be strong.

\section{Our Wishes for Future Generations}

When recommendations and dreams for future generations were made regarding the future, all participants thought we would be best to return to our original teachings and build a foundation based on our worldview in order to support future generations. The Elders in the study recognized the thirst that our children, youth and young adults have for their culture and 
they believe that this seeking of cultural knowledge is the way to move forward. "This is where our power comes from." (Elder). "We need to become self determined people, with our old values and our old roots." (Autumn) "We need to design a new way based on our original way that will work in today's society but not based on the colonial structure we are currently in." (River)

Individually it was thought that our future generations will choose for themselves how they wish to identify. The hope is that they will not be as influenced by the government and that they will decide based on how they feel and that it will no longer be decided for them at birth but that they will have the freedom to choose what is best for them. Autumn felt that if our children had the ability to choose without restrictions they would feel more happiness and strength.

As far as the community was concerned, it was shared that we need to stop looking at our children for their monetary worth. Currently due to government legislation and our dependency on the government, people who are recognized as being status have a monetary value attached to their identity. Monetary value is determined by status. The government provides communities with monies for each status Indian that is a member of the community. This member allows bands to provide services to its members such as education, transportation and health support. This monetary support helps the community to help its members and is influential in how they grant membership and allow access to programming. "Having access to programming and support is influential in a person's feeling of belonging and acceptance."(River) This influences a child's feelings of belonging. Each participant hoped that eventually we would not have to depend on government support and would be able to determine for ourselves who would be part of our community based on an individual's connection and relationship as well as their ancestral 
connection. "We will never solve our problems if we focus on the money. We can't and shouldn't put a dollar value to our children" (River).

The hope is that our future generations recognize the interconnectedness of everything. "That they will have pride and respect so that they do not feel the need to oppress others in order to feel strong." (Wind) "I want them to embrace and be accepting of all people and not judge people based on external factors."(Autumn) "Being respectful and open, they will feel pride and be able to hold their heads high and know that they are good Anishnaabe people." (Elder)

The Elders in the study all viewed education as an important tool for our future. Though they all recognized that we need to focus on our own culture and worldview they felt that in order to be on equal footing and able to create change in this world we need to be educated in the mainstream way. This does not mean that we don't keep our worldview and ways but we must live in both worlds successfully in order to be strong and create positive change.

They also all felt that we need to move forward. As an Elder put it, "We must move forward. We don't have to like what happened but we are not going to get any further if we hold on to the past. We must go ahead and do the best that we can." Forgiveness does not mean forgetting, but it allows a person to move ahead and focus on what is important now.

\section{Final Comments on Findings}

In this chapter, I documented how the participants in the study felt influenced by the Indian Act and Bill C-31, how this reduced their feelings of choice and power while sharing their wishes for future generations and how they will be made to feel and belong within their First Nation. The examples provided in this paper allowed for the participants voices to be heard and my hope is that the reader will understand how influential and detrimental these pieces of government legislation have been in the lives of these women. For most people in Canada, a 
person's connection to their family is not challenged or questioned by the government but for these women they have had to overcome many obstacles that have impacted their relationships within their community and the relationships of their future generations. In the following chapter I will discuss the need for change to the Indian Act and Bill-C31. I will discuss how this legislation goes against the "United Nations Convention on the Rights of the Child" and how communities can support their future generations to develop a positive sense of identity and a feeling of belonging within their community. 


\section{CHAPTER 5: DISCUSSION}

The purpose of this study was to bring awareness to the effects that the Indian Act and Bill C-31 has had on the identity of First Nations women from Georgina Island. This study was conducted due to the researcher's own personal connection to this topic and her relationship with the women in the community with whom she has had lifelong relationships. I felt it was important to share their stories of resiliency, strength and their visions for the future. Identity has been a struggle for the women who participated in the study, but it is also their strength. They have adapted to their world and have come out strong and resilient.

I have taken on the responsibility of sharing these stories for the community, for other First Nations communities, academia and others who may find this information meaningful and useful in their life's work. My initial intention of this research was to bring awareness to the struggles and obstacles faced by First Nations women in their identity development. During this process I have come to realize that what I really determined was that, though we have all meet many challenges and struggle due to the legislation, we all value our community and the feeling of belonging to it and our ancestors. I understand that community, belonging, and identity are all interconnected as all things are, but the focus that came out of my interpretation of the sharing and my research is that what really matters is community and an individual's choice in their connection to this community. This connection and feeling will support future generations in their process of self awareness and positive identity development, hopefully leading to health and happiness.

My initial intention was to use sharing circles to collect data. I soon realized that even though we are all close and share many thoughts and feelings with one another, there was discomfort for many in sharing feelings regarding this topic. The division within families made 
some participants uncomfortable to share their intimate thoughts in a group for fear of hurting another. The division created by the legislation makes people feel as if they are alone in their struggle with status and identity, there is anger about the unfairness and this was quite apparent when asking for sharing circle participation regarding this topic. For a few of the participants, time constraints impacted their decision to have one-on-one interviews. They struggled with finding a time when they could meet up with others and it was easier and less stressful to pick a day and time which they were available. Though I had desired group sharing, it was more important for me to be flexible and accommodating to those participating in the study. This flexibility is also a key component of indigenous methodology.

The following discussion centres on my interpretation of the contributions made by the participants, and the literature in relation to children's rights. I would like to recognize the role that my ancestors and community play in this process. Through this study $I$ have been able to gather greater insight into what effects the legislation has had on the women in my community and how together we can support future generations in a way that is inclusive and meaningful; recognizing their rights to belong and identify how they choose with the hope that they will feel pride and strength from their community.

\section{Influence of the Indian act and Bill C-31}

The Indian Act and Bill C-31 influenced the lives of each participant in the study. It challenged their sense of belonging within their community. It influenced how they viewed themselves in relation to others and has been an obstacle throughout their lives. This piece of legislation removed First Nations people's way of living, removing their decision making power. The removal of their ways of living has placed enormous obstacles in the development of a healthy identity for many (Wesley-Esquimaux, 2007). Historically, connection to community, 
culture, and identity was determined by clans, language, and culture. The Indian act was created to control and assimilate First Nations people into Eurocentric society by making their traditions illegal and punishable. This research found that the Indian Act was somewhat successful in its assimilation with older generations as they feared the passing on of language and tradition. Autumn shared that she was unable to gain traditional knowledge from her father. Her father feared that to pass on traditions would be passing on the hurt and abuse which he had been subjected to in the education system and when he participated with communities outside of his First Nation. The participants shared their sadness about the loss of language and culture that they felt.

When we ignore our cultural identity we are sometimes given a false sense of power (Bonetskaia, 2004). This avoidance of our norms or our inability to learn our ways due to limited teachers and elders led us to die a spiritual death. The more we embrace ways that are not our own the stronger the government becomes over us. In order for the Canadian Government to reach their goal of assimilation we must be convinced of our inferiority and need for help. The more downtrodden we are the more we will unknowingly want to be like the majority. We will be convinced that in order to have success we must be like them because they are right (Freire, 2000). During a time of sharing, one of my Elders shared her concern that we keep becoming more like the mainland. She stated that neighboring municipalities are not always right, but expressed concerned that we follow anyways.

Not only do we need to hold onto our ways, we need to support our children in learning their traditions. Autumn struggled with her lack of cultural knowledge and worried when it was time to teach her own children. An Elder wants us to not feel lacking in knowledge but to find support. She shared that there are lots of people who will help. One just has to find them. Our 
Elders want us to seek them out. They hold our ways and we need to ask them to share their wisdom. She expressed seeing our children as hungering for our culture and language and she encourages us to guide them in learning so that they will know and they will be proud. We cannot feel that we are lacking as parents. There are reasons we do not have our teachings and we need to recognize those reasons and move forward. It was not due to our lack or inadequacy, but to colonization by the Canadian government.

\section{Identity}

Each participant had their own struggles and challenges with identity due to the legislation. For all participants it affected their ability to make choices for their children in regards to identity and community. Identity development is a lifetime process which is influenced by our relationships, our community, language culture and the policies and social structures which surround us. The development of positive identity is important for all. People who have a positive identity are able to be balanced emotionally, mentally, spiritually and physically, allowing them to live healthy, fulfilling lives (Morrison \& Bordere, 2001). A repeating theme that emerged from the participants' stories was a desire for happiness for our future generations. In order for our children to find happiness they need to develop an identity that is meaningful to them. This development cannot be controlled by the government at their birth. They need to be able to embrace what feels right for them, have a connection to their family without restrictions and live where they choose. The Canadian government with the support granted in the Indian Act and Bill C-31 determines the identity of the child at birth based on the requirements they have set out in these acts. Indigenous people in Canada are the only ethnic groups whose identity is dictated by the Canadian government. Other ethnic groups do 
not have their identity determined by the Canadian government upon birth, their family or selves are able to decide which ethnic group they will connect to and identify with.

Indigenous children's identity is an issue of equity and social justice (Carriere \& Richardson, 2009), Our children's identity can no longer be controlled by whether they qualify according to government restrictions. For all other Canadians "Citizenship under Canadian law is not restricted to persons who qualify at birth" (AFN-INAC, 2008, p. 22). Why is it then ok for the government to determine this for Indigenous people? Throughout the sharing of life stories the participants reflected on the judgment they felt by the government. Frances shared that she felt like we were judged in the same way as beef, except that she does not feel that the government looks at us as 'grade A beef' but rather dog food. The government should not have the right to judge us at birth. They must recognize that "identity can only be confirmed by those who share that identity" (Weaver, 2001, p.245). The sharing of stories by the participants and the literature speak to the importance of choice for individuals in belonging to a group. The participants shared that the legislation removed their ability to have choice and freedom. It is up to us individually, as a community, and as a nation to determine how we will identify. We must recognize that enforced identity is an aspect of control by the Canadian government or more fitting, by the colonizer (Sedinger, 2002). Identity should not be determined by an outside source that does not have the best interest of our children or community at the forefront of their decision making.

\section{Community}

Lack of choice and influence has created division within families and communities. Ties with family have always been the foundation of First Nation societies and identity. The legislation has interfered with this foundation (AFN-INAC, 2008). For many Indigenous people, 
a community, and its people validate who they are and provide a place of belonging. Many Indigenous people identify themselves by their 'reserve' or community (Weaver, 2001). When you ask an Aboriginal person who they are they generally will tell you the community that they come from (Frideres, 2008). Dislocation from community has been shown in this study to negatively affect belonging and identity. Many people who have grown up outside of their communities feel a sense of distance and loss of their ethnic identity (De Souza \& Rymarz, 2007). With the absence of community there becomes a division and sense of us and them, making those who do not or are unable to live within their community to feel as if they do not belong anywhere (De Souza \& Rymarz, 2007). They lose their sense of connection and support which leads to feelings of loneliness, depression, and low self esteem (Carriere \& Richardson, 2009) was expressed by River who spent years feeling as if she did not fit in anywhere.

For the participants in the $30-49$ age groups, they thought that their connection to community was determined by the community itself and how 'Indian' the community thought that they were. River was one such participant when at the age of 16 she gained status and realized that it was in fact the government who had decided that she did not belong. She had always thought that she just did not measure up. The legislation is very subtle in how it creates division and feelings of exclusion and inadequacy for many. We have to become aware of the root cause of this division rather than blaming each other.

Throughout this study I noticed a strong underlying theme; the community and a sense of belonging are what matters. For instance, Autumn felt that community was all we really had and nothing else really matters. This seemed to become the main theme of the study. Regardless of status, regardless of those who were rejecting of others, regardless of the past, when all the cards are on the table and push comes to shove we are one. We are a community and our children will 
be connected as their children will be. It is something we need to honour. It is something we need to encourage. It is all that we have.

The Canadian government does not appear to recognize the importance and connection between identity and community, or do they? I question their intentions. Have they changed or do they still have the original goal of assimilation for Indigenous people (Lawrence, 2003)? How do we stand here and support a government whose goal is to exterminate a population? When we hear about genocide in other countries we are appalled by it, but here we sit in a country that pats itself on the back for living 'right' when in fact we are living the same way as those we accuse of being backward and unlawful.

\section{Generational Difference}

Though there were many similarities in the internal struggles felt by these women, there were distinct differences in how the age groups were affected. The $50+$ women were always aware of the power that the government had over them, while the $30-49$ age group were not. The $50+$ age group had their status removed from them upon marriage while the 30-49 age groups kept their status upon marriage, but may not have been able to pass it on to their children due to the third generation clause (Daniels, 1998).

The women in the $50+$ age group grew up being more aware of the control that the government had over them by seeing children being removed by Indian agents to attend residential school. The removal of children or threat of removal was traumatic to the whole community. One Elder shared that it was well known that if you did not act a certain way or the Indian agent disapproved of your family then you were probably going to be taken away. This enforced the removal of Indigenous ways of life. The traditional purpose of Indigenous communities was to provide a place of balance in order to support the rounded development of 
their children. Children are looked at as a gift from the creator (Greenwood, 2006). When communities were threatened to have their children taken away it created fear and struggle for even the young and took away a community's purpose. I feel that over time the threat diminished somewhat due to people's ability to live the Eurocentric way, which reduced the disapproval by outside 'helpers' who felt they were in fact 'helping' the children. The reduction of threat within Indigenous homes likely reduced the awareness that children had regarding to what extent the government in fact controlled their lives. Besides causing threat to the family systems within community, the legislation created other restrictions. For instance, the participants shared that the legislation influenced their ability to participate in full time employment, purchasing of goods for their families, extracurricular activities for them and their children both inside and outside of their community, their education, and who they married.

Though the Indian act has been detrimental to all Indigenous people in Canada it has created even greater barriers and challenges for Indigenous women (Lawrence, 2003). For many of the women in the $50+$ group having to live outside of their community was enforced upon them due to who they married. Native women who fell in love with non-native men had their status removed which took away their ability to live and participate within their First Nations community. This was a one sided restriction, as Native men who married non-native women were able to pass on their status to their wives, their children and grand children. The children of these women who had status removed had to grow up outside of their community without status until Bill C-31 was introduced in 1985. When this Bill was passed it gave First Nations women the ability to apply to have their status reinstated. One Elder shared that it was demeaning to have some man tell you that you were now in fact an Indian. She said "I always was an Indian". She thought who was he to tell me who I am. For others, it was the rejection that was 
challenging. Gehl (2000) describes a time when an Indian women made a claim to Indian Affairs to ask what in fact her status was. She was told that she was now in fact a white woman and that she ceased to be an Indian.

For the women in the study the return of status was very meaningful to them. Bill C-31 allowed them to move home, it gave them a voice in their community, and rekindled relationships within. For others it created greater divide. The women who had their status removed were able to pass on their status to their children, but unlike the men who had married non-native women they were not granted the same right to pass status to their grandchildren. Bill C-31 was sold as creating equality between men and women when in fact it was incomplete in this 'goal'. Freire (2000) believes that when you make requests from the oppressor what in fact you will be given is further barriers. With Bill C-31 we were given 'false generosity' that created new barriers between families. Concern was felt by the participants regardless of how the legislation restricted them and their children. I believe this was viewed as a concern for all because it creates division between today's children and families within the community. For some participants in the study their siblings' children or grandchildren may have status while their children do not. This creates an uncomfortable struggle when what we all want is unity and for no one to feel excluded.

In April 2009, the Court of Appeal ruled in favour of Mclvor, who challenged that the Indian act discriminates between men and women (INAC, 2010). The government is currently on its second extension to these amendments but has yet to adjust the act and return the rightful status to these children who are still living without access to community programming, education and services. We cannot count on the government to free us from these restrictions. We need to stop looking to them for our approval and move away from their support. River recognized that 
we need to stop placing a dollar value on our people. Right now the government determines who is worth money and who is not. Children who are recognized at birth as having status are funded by the government within their community. Without status a person does not have treaty rights so they are not included in the government treaty funding. The amount of funding that a community receives from the Federal government is determined not by the total population but by the status population within a First Nation. The funding provided is insufficient and low and attempting to support everyone with ancestral ties would put further strain on a communities' ability to meet the needs of the community. We must recognize that by excluding people we are further colonizing them and increasing the division between families and community. We must become independent and able to include all, once this happens we will be able to make our own decisions and be inclusive. Change for First Nations communities is a challenge. We live in both societies and our power is located outside with the Federal government (Freire, 2000). We are financially controlled by the Federal and Provincial governments through funding. Since many of our children are educated outside of our community, the government influences their culture and language through curriculum As long as we remain dependent on the government they will continue to offer us false hope which in fact created more barriers.

\section{Education}

In order to be able to navigate both worlds successfully our children need to receive an education which will support them in gaining appropriate knowledge while honouring their individuality and culture. Currently, many First Nations people struggle with the education system. This may be influenced by the role that education played historically in the lives of Indigenous people in Canada. Education was to take the Indian out of the child (Takeda \& Williams, 2008) and to 'civilize' them. Egerton Ryerson, the namesake of Ryerson University, 
had an enormous influence in educating 'Indian' children. He felt that it was best to take parents and communities power away and give control to teachers and missionaries so that we would learn agriculture knowledge apart from 'white' children who were learning in grammar schools (Carney, 1995). This set up speaks to the goal of taking us away from our culture and traditions but to have it replaced with something less than was provided to 'proper' and 'civilized' children.

Theorist Homi Bhabha believed that the goal of colonizers is to make those they are colonizing to be like them thereby ensuring that they are easier to deal (Mageo, 2008). Elder 'Frances' during her sharing recognized that traditionally education was used in detrimental ways in regards to our children. The discrimination which the families of today's First Nations children faced while being 'educated' has left a gap in the transfer of identity, pride and spirituality. In addition to the desire for us to be like them, Bhabha believed that those who are colonizing do not want the colonized to have success but to experience (or feel like a failure) failure. This feeling of failure helps to ensure inferiority to the colonizer and removes our sense of entitlement (Mageo, 2008). Though Bhabha was looking at all interactions and not simply education, it is fitting that the system that Indigenous children find themselves does not reflect their worldview, culture or language ensuring barriers and limited success when participating.

Our children must no longer be educated in a Eurocentric system. We must ensure that they do not spend their days feeling inadequate but that they find themselves supported in an environment that helps to strengthen their self esteem and provide them with the tools they will need to overcome any challenges and struggles they may come across (Phinney, 2008). Aboriginal children in Canada are behind all other Canadian children in educational achievement, this reduces their ability to close the gaps in socioeconomic status and quality 
employment attainment (Canadian Council of Provincial Child and Youth Advocates, 2010). In order to achieve equality within society they must find success and be supported in the development of 'their' positive identity. Education can be used to create equality and right the wrongs of the past. "History does not disappear; it is the foundation of the present and the future" (Rae, 2006, p13). Education should provide a foundation and give people the ability to make change that supports their human rights (United Nations [UN], 2009). In order to support Indigenous children in the development of their identity they must feel that they belong and that their beliefs are valued by all of society's systems.

The Elders who participated in the study all felt that education was important for our future generations. One Elder shared that education will give us strength and support us in making positive change and gain self determination. Another Elder recognized that those who are educated will be the ones to contribute to the strength of our community. Frances believed that education will reduce the prejudice and create positive change in our world. Mainstream education should focus and support all cultures so that we gain an understanding and respect for all others. One Elder shared that until all races can all live in harmony we will never be able to heal Mother Earth. This supports the importance of providing an education which honours all and reduces the barriers. In order to provide support to our future generations we must ensure that they are educated and that their education is meaningful and supports them in finding later success.

\section{Struggles}

The Indian act and Bill C-31 create struggles within the community. We not only struggle with our identity due to legislation but we constantly have to justify and prove ourselves to others both inside and outside our community (Weaver, 2001). The constant fight to prove self is 
tiring and troublesome. It is problematic for people to have their identity determined for them by an outside source, then not to receive that validation from their community members (Weaver, 2001). The majority of the participants shared that at some point throughout their lives they have been made to feel as if they were not enough by their own people. These feelings of being less than or not enough make us feel inadequate. River felt up until adulthood that she did not fit in anywhere. She was too white for her community but too Indian for outside society. Autumn, although dark haired and dark skinned, shared that she was half 'Indian' and she had family who could make her feel white as snow.

When people feel oppressed they will fight to gain power. If they are unable to find strength by creating change they will oppress another to gain that power (Freire, 2000). I believe that this is what happens in First Nations communities. People are feeling controlled by both the federal government and their nation's government. This frustration and inability to change the way things are, leads people to look for power another way. This is played out by community members with higher feelings of entitlement taking it upon themselves to make their family and community members to feel that they are not 'Indian' enough and they are only 'half-breeds'. River shared being called a Shaganash (white women) by community members. Those needing to gain power do this without recognizing that they are gaining their strength at the expense of their community members, who are their 'family' (Freire, 2000). Theorist Mikhail Bakhtin felt that in order to make change we must communicate and to communicate is to take action (Irving \& Young, 2002). When people who are similarly oppressed begin to talk and recognize their oppression and oppressive ways they are able to create positive action on a larger scale (Vodde \& Gallant, 2002). In order for our children to feel a strong sense of cornmunity we must recognize what is happening within and the negative impact that it is having on our children and 
families. When we recognize our weaknesses we can turn them into strengths through our dialogue and actions.

\section{Reclaiming \& Rebuilding}

Our teachings instruct us to plan for the next seven generations. The sharing that took place in this research included stories of the 'way it was' and how our parents felt. When we speak our words carry with them our prior relationships, experiences, and history (Irving \& Young, 2002). Self determination, choice, happiness, and pride were looked at as necessary by all participants. Participants believed that our children should feel good about themselves and their connection to the community regardless of government approval. Supporting a strong connection to community and family will support our children in overcoming the stigma and challenges which they may face throughout their lives. When children have a strong connection to their community, they will not believe the negative stereotypes that may be attached to their group. Rather they will be aware of their groups' strengths and abilities (Shih, 2004).

Colonization was viewed by Frances as a clash of two worldviews, which led to the development of the Indian Act. Our worldview is about the interconnection of all things, independence, equality, connection, and balance. The participants shared our need to create cultural renewal based on our old ways in a new way. Having pride in traditions, culture and language were looked at as important to the future of our children. Recognition that our Anishnaabe culture is not out of date, but that it is adaptable and able to meet the challenges our children will find throughout their lives and participation in today's society. This evolution of traditions will support future generations in leading healthy, happy, and productive lives both inside and outside of our culture. The adaptation of our culture supports our children in having a strong foundation on which to grow and find success within the world they find themselves. 
Seeing the value and strength of all people was seen as an asset for the participants in this research. Autumn shared that her wish for her children is to be respectful of all people and to learn from each other. I believe that this respect and sharing of knowledge will support our future generations and will further support their growth and development.

In conclusion, what we all truly want for our children is for them to be happy. We need to recognize that they have the right to live free from discrimination, to have the right to choose their identity, the right to their culture and the right to be educated in a way which supports their development. Parents have the right to determine the best interests of their children, Freire (2000) believed that people cannot liberate themselves or others, but that in numbers people will be able to liberate each other.The future of Indigenous people in Canada is dependent on the children of today. We must work to ensure that Indigenous people's rights and Children's rights are addressed in regard to the Indian Act and Bill C-31 so that future generations will be able to build their foundation on a history of pride and dignity, which honours their history, their culture and their communities. It is not enough for us to know the problems of the world. It is our responsibility to be a part of the solution (Rae, 2006). We have an obligation to ensure that all children grow in a world which honours them.

I believe that our community is strong and will be able to overcome the challenges that have been and will continue to be felt by the Indian Act. Though we struggle with boundaries, we recognize the importance of one another. We come from a place where our children are our top priority. We know each other, understand each other, and share the same stories. We have a history together and feel a connection which cannot be determined by a piece of paper. We are family and when push comes to shove we will stand up and fight for our community and its members. It is who we are. We are connected and we are one. 


\section{Limitations and Strengths}

One limitation of this study is that the researcher only looked at one First Nation community. Therefore the findings do not represent all First Nation communities in Canada. This study may also be further limited since the researcher only interviewed women in this study who have been marginalized and directly affected by the Canadian government's legislation and policies in regards to status, and did not hear the voice of the entire community. Research hearing the voice of all community members further support this study and provide a larger voice.

Additionally, as a researcher I acknowledge that being a community member, an "insider" may be a drawback and that the participants may have not been totally open with their feelings during the sharing though I intended to provide an atmosphere free of judgement which was respectful.

On the positive side, having a lifelong relationship with these women provided me a rapport that other researchers would spend years building. As well, the contributions made by the participants will be respected and shared in the ways how they wish it to be shared and this study gave voice to the challenges and struggles met by these women during their lives and shows their strength and commitment to their community and to the generations to follow. 


\section{CHAPTER 6: CONCLUSION AND RECOMMENDATIONS}

\section{Conclusion}

This study was conducted to share the stories of the women in my Georgina Island First Nations community who have been challenged and governed by the Indian Act and Bill C-31. Through an indigenous and a critical framework I was able to gather the stories in a way that best suited my community and allowed me to bring awareness to the feelings of the participants in order to hear their voice and recommend change that will support a forward movement and positive change for our future generations. In this chapter I will reflect on what matters to participants, surprises I encountered in conducting this research, my personal journey and reflection, and recommendations for future research.

I set out on this journey because I wanted to share the stories of the women from my community who have felt the impact of the Canadian government legislation known as the Indian Act and Bill C-31, and to find a way to ensure that our future generations will be supported in their identity development within the restrictions and barriers put in place by our Canadian government. By listening to the stories of these women and reflecting on what they felt was important in their lives, I found out that although we have all been immensely influenced by the legislation it is our connections and our community where we find our strength and ability to overcome these challenges. A unified voice came out and it shared that all that truly matters is community, and though we all recognized the internal struggles and challenges it was important for all with ancestral ties to our Nation to be recognized and welcomed as being part of our larger family. 


\section{Surprises of Conducting Research}

Many things surprised me during this research journey. I was overwhelmed by the number of people who heard through the grapevine that I was conducting research. I was also surprised by the interest and desire of people to share and hear each other's thoughts. The number of people who are waiting and excited to read this is astonishing and I am honoured by their interest. I look forward to further research and sharing of our stories in order to bring awareness and positive change. I hope that we will one day have unlimited access to journals and articles that are written by Indigenous researchers which share our stories. I believe that there are many areas that need to be looked at but through this study I feel that the issue of status and relationships both inside and outside of communities need to be looked at more deeply. An extension to this study which hears the voice of our children and men would honour them and give them the opportunity to share their view on the issue of Indian status. I would love to see someone journey into the issue of status outside of the community, where local businesses, peers and service providers question and disapprove of our uniqueness and access to our treaty rights. My hope is that with more Indigenous researchers we will be able to bring a voice to all which matters. It is the journey of the individual to decide and be guided towards what they should write about. This will support them in being passionate and writing with meaning for them and their community.

I was surprised by the anxiety that sharing together in a large group brought. We are all very close and spend lots of time eating, dancing and laughing together but when this topic and questions were introduced it brought with it a silence and aloneness. In the end we all shared many of the same feelings but I believe the anxiety may have been fear of hurting another person's feelings regarding internal division within families thus reducing a person's ability to be 
totally open in our sharing. The personal interviews that I conducted provided me with great quotes and deep thoughts and feelings. I had expected this from the sharing circle, but found that the sharing wasn't direct. Feelings were shared about inequality between men and women, but I felt that there was some holding back in comparison to the personal interviews.

My deepest surprise was my struggle with how to share what participants shared about our community's internal challenges and oppression. I considered not sharing it. I went to an Elder who told me I would know what to do, and I asked my Indigenous supervisor for support. I was guided into putting down tobacco and asking for guidance. After a couple days off from writing and coding I sat down and began again. From this point on my writing has flowed out of me, I have felt guided, and supported in both my thoughts and writing by who I believe to be my ancestors and a force greater than myself. I wish to extend my gratitude.

\section{Recommendations}

My first recommendation is that all Indigenous researchers use an Indigenous framework and do not feel the need to further support it with another framework. I was guided in my research methods course to support the Indigenous framework with another dominant framework because it was felt the Indigenous framework could not stand on its own (colonization within academia). What I learned is our framework can stand on its own. I encourage you to follow your heart when writing and use our framework within our communities.

Further recommendations that emerged from this research. I recommend that the Canadian government bring the Indian Act and Bill C-31 into alignment with Indigenous worldview, the Canadian Charter of Rights and Freedoms, and The United Nations Convention on the Rights of the Child. The government must recognize that Indigenous children deserve the same rights as other Canadian children. In order to align the Indian Act and Bill C-31 to reflect 
an Indigenous worldview, the charter and the convention, a partnership needs to be set up between Indigenous communities and government policy makers. This partnership will help to ensure that Indigenous people's voices are heard and the changes reflect their worldview and beliefs for the future of their people.

I recommend that my community continue to work together to support all our children in the development of their identity, while embracing all people with ancestral connections into our community. This can be done by continuing to provide cultural opportunities both inside and outside of our schools and childcare centre. Having a yearly 'family' reunion which is open to all with ancestral ties, could provide an opportunity for us to learn our traditional games and break down barriers through friendly competition. An Elder in this study suggested having a meeting once a month to look at our history and our family trees so we remember where we came from and recognize our connection. These meetings will help to ensure that our future generations know their ancestral connections and give them pride through this sharing.

I recommend that the education system revamp their system and begin providing Indigenous children and all children with an education which is meaningful, where they can see themselves positively reflected, have success in an environment which ensures they understand the importance of being gentle and respectful to Mother Earth. In order to do this we must recognize 'everyone's' strengths. I believe that all people should have a say in the lessons being provided to their children, we must come together to share our dreams and visions so that the curriculum being provided can reflect that. Curriculum needs to be developed by a multicultural panel of experts, excluding none, who can ensure that all children will see themselves positively reflected. During this study one Elder shared that until we can all live together harmoniously we will never heal 'our Mother'. 


\section{Dissemination}

In keeping with an Indigenous approach to research this major research paper will be disseminated to the community. Copies will be provided to the Georgina Island Chief and Council and the Georgina Island Library. A summary of findings along with a visual presentation will be shared with the participants and the community at our Welcoming Ceremony for our Children on September 23,2010. At this time I will be available to share the research project. The visual display used will be given to the library for their sharing, if they wish. A summary of this paper will be provided to Child Welfare workers from Alderville, Curve Lake and Beausoleil.

\section{Personal Journey and Closing}

When I began this journey I was not aware of the sadness that I carry deep within me regarding our loss of culture and my fear for our future generations. As a 6(1) and having children who are 6(2), I feel that we are spiralling towards a finish line which we had no intention of racing towards and which we do not want to cross. I cry when I feel that my future generations may be rejecting a relationship and connection to me, my ancestors and our community. My sadness reaches past me to my ancestors whom I still am connected and to my family who may not be reaching the 'finish line' as quickly. I discovered through this journey that I am not alone in my sadness and fear. For too long we have been governed by people who do not understand or don't care about our connection, who base our belonging and membership on a dollar value and feel that we should just walk from our community and family away when they determine our identity is done.

What this study did for me was to reinforce my belief that we need to move away from allowing the government to dictate who belongs within our community, take the dollars off our 
children, and embrace a deeper connection based on our communities culture, language, connections, and traditions. I will work to remove the influence that status has had over me and my children. 1 will bring a voice to our wishes for future generations and encourage a future based on our original worldview, our culture, our language, and our connections. I believe we are strong and resilient and will overcome the generational affects of the Indian Act seeking our own way again. I believe we will eventually remove our-self from government control and become able to determine our own membership, one that is not focused on money and status but strength and unity. I am a believer. I believe in my community and my people. 


\section{APPENDIX A: CONSENT FORM}

You are being asked to participate in a research study. Before you give your consent to be a volunteer, it is important that you read the following information and ask as many questions as necessary to be sure you understand what you will be asked to do.

\section{Investigator:}

Carolynne Warton, Georgina Island Community member. Bachelor of Arts, Early Childhood and Family Studies. Master of Early Childhood Studies (MAEC) Candidate. Ryerson University, Toronto.

\section{Participant selection:}

The participants will be selected based on one or all of the following criteria: women who married a non-status person, whose children have been affected by the legislation and Bill-C31, and those women whose grandchildren are affected by the legislation and bill. The women will all be from Georgina Island or have ancestral ties to the community.

\section{Purpose of the Study:}

To determine how Canadian governmental legislation has affect the identity development of the Georgina Island First Nations.

\section{Description of the Study:}

$>$ The sharing circle location will be determined by the participants.

$>$ The study will take place in a relaxed conversation. I have relationships with the women participating in the study.

$>$ I will open the sharing circle by re-introducing myself and the project.

$>$ If the women participating in the interview wish to open with a ceremonial smudge I will have my medicines with me and will ask if someone wishes to do the smudge otherwise I will do the smudge (Smudging is the burning of our sacred medicines, which can include all or some depending on whose is doing ceremony. The four medicines are tobacco, cedar, sage, and sweet grass. This cleanses and purifies mind, body and spirit and allows for a positive place to begin sharing.

The women will be asked:

- Did the Indian Act impact how you viewed yourself as an Anishnaabe woman?

- Did it influence your relationship with the community?

- Have you ever felt restricted and controlled due to the legislation? (Marriage, children)

- What are your wishes for future generations in regards to how they identify?

- Do you believe that children will and should have a relationship with their community even once their status ends?

- How do we support our future generations?

When the sharing circle ends the researcher will ask if the group would like to share in another smudge if what has been shared makes them feel the need to be cleansed. 


\section{How information will be recorded:}

The sharing circles and conversations will be taped and notes will be made which will reflect the study and the conversations.

\section{Confidentiality:}

Audio tapes will record the sharing circles and interviews. They will be destroyed after one year, after being transcribed into writing and analyzed. The written analysis will not contain the names of participants. The analysis may be read by my supervisors Dr. Lynn Lavallee and Dr. Rachel Berman.

In sharing circles, what is said in the circle stays in the circle. So I hope that the information shared by individuals will not be taken out by others within the circle, though I cannot make any guarantees.

\section{Compensation:}

The participants will not be paid to participate in this study. Refreshments will be provided at the sharing circles.

\section{What is Experimental in this study?}

None of the procedures used in this study are experimental in nature. The only experimental aspect of the study is the gathering of information for the purpose of analysis.

\section{Risks or Discomforts:}

Due to the personal nature of the questions, you may reflect on unpleasant memories while responding. If at any time you feel any discomfort, you can stop participating temporarily or permanently.

\section{Benefits of this Study:}

The benefits of this study are to bring a voice to the challenges that women within First Nations communities have dealt and to work to determine ways to support our children in the development of positive identity development.

\section{Voluntary Nature of Participation:}

Participation in this study is voluntary. Your choice whether or not to participate will not influence your future relations with myself as a friend, community member, support worker or with Ryerson University. If you decide to participate, you are free to withdraw your consent and to stop your participation at any time.

At any particular point in the study, you may refuse to answer any particular question or stop participation altogether.

\section{Questions about the study:}

If you have any questions about the research now, please ask. If you have questions later about the research, you may contact.

Carolynne Warton@ cwarton@ryerson.ca, or 289-338-1622 
Dr. Lynn Lavallee@ lavallee@ryerson.ca or 416-979-5000 extension 4791

Dr. Rachel Berman@ rcberman@ryerson.ca or 416-979-5000 extension 7695

If you have any questions regarding your rights as a human subject and participant in this study, you may contact Ryerson University Research Ethics Board for Information.

Research Ethics Board

c/o Office of the Vice President, Research and Innovation

Ryerson University

350 Victoria Street

Toronto, Ontario M5B 2K3

416-979-5042

\section{Agreement:}

Your signature below indicates that you have read the information in this agreement and have had a chance to ask any questions you have about the study. Your signature also indicates that you agree to be in the study and have been told that you can change your mind and withdraw your consent to participate at any time. You have been given a copy of this agreement.

You have been told that by signing this consent agreement you are not giving up any of your legal rights.

Signature of Participant

Date

Signature of Investigator

Date

I consent to the conversations being audio taped.

Signature of Participant

Date 


\section{APPENDIX B: LETTER TO CHIEF AND COUNCIL}

Georgina Island Chief and Council:

\section{Re: Thesis requirement for completion of Masters of Early Childhood Studies, Ryerson University.}

As the band may be aware, I have been working towards completing my Masters of Arts degree in Early Childhood Studies. I have completed the required course-work and am now beginning the thesis stage of my program. I hope to finish by late November or Early December. I would like to attach a letter of permission from the Island to my ethics proposal to the university allowing them to see that I have shared my research idea with you and that it is alright for me to do it.

I am looking at identity development and how legislation (Indian Act \& Bill-C31) has influenced this development. I will be interviewing women who have had their status removed and then reinstated through bill C-31 and how it impacted them, their children and grandchildren. I will ask these people for individual consent to participate but thought that it would be important to have your approval as well as Council, and didn't want you to hear about my research from those participating.

Why I am doing this research...I think it is important to bring awareness to the impact that this legislation has had on some of the women in our community and to give it a voice. I hope to determine how children can be further supported so they will always feel a sense of connection, pride and strength to their ancestral ties regardless of how the government views their connection, and to decrease the impact that these policies have on their individual and cultural identity.

I want to work within our community on a topic I hear and see has impacted us for generations.

I hope that you will see the value in this research, and support me in going forward with it. If you want to meet next week, I can provide you with more information.

Miigwetch, Carolynne Warton (Porte) 


\section{APPENDIX C: GUIDE FOR SHARING CIRCLE}

Sharing Circle Procedure:

- Introduce myself (name, ancestry)

- Re-introduce project and my role

- Sign consents

- Smudging ceremony cleanses and rids people of any bad feelings, negative thoughts and allows for healing to happen. This will help to provide a positive place to begin the sharing.

- Describe how the legislation has affected my life $(5 \mathrm{~min})$

Questions - The women will be asked:

- Did the Indian Act impact how you viewed yourself as an Anishnaabe woman?

- Did it influence your relationship with the community?

- Have you ever felt restricted and controlled due to the legislation? (Marriage, children)

- What are your wishes for future generations in regards to how they identify?

- Do you believe that children will and should have a relationship with their community even once their status ends?

- How do you believe we can support our future generations?

Notes:

Participants will be asked to meet with me individually if they chose to share anything they did not feel comfortable sharing in the group. It will be optional for participants to take part in one on one interview.

When the sharing circle ends the researcher will ask if the group would like to share in another smudge if what has been shared makes them feel the need to be cleansed. 


\section{References}

Assembly of First Nations \& Indian and Northern Affairs Canada. (2008). First Nations Registration (Status) and Membership Research Report. Lands \& Trust Services, Ottawa Ball, J. \& Simpkins, M. (2004). The Community within the Child: Integration of Indigenous knowledge into First Nations childcare process and practice. American Indian Quarterly, $28(3-4), 480-498$.

Bonetskaia, N. (2004). Mikhail Bakhtin's life and philosophical idea. Russian Studies in Philosophy, 43(1), 5-34.

Canadian Council of Provincial Child and Youth Advocates. (2010). Aboriginal Children and Youth in Canada: Canada must do better. Retrieved on August 21, 2010 from http://www.gnb.ca/0073/PDF/positionpaper-e.pdf

Canadian Institutes of Health Research (2007). CIHR guidelines for health research involving aboriginal people. Aboriginal Ethics Working Group. Retrieved on February 21, 2010 from http://www.cihr-irsc.gc.ca/e/documents.ethics_aboriginal_guidelines_e.pdf

Canadian Mortgage and Housing Commission. (2010). History-CMHC Milestones. Retrieved August 2, 2010 from http://www.cmhc-schl.gc.ca/en/corp/about/hi/hi_001.cfm

Carney, R. (1995). Aboriginal Residential Schools Before Confederation: The early experience. CCHA, Historical Studies, 61, 13-40.

Carriere, J. \& Richardson, C. (2009). From longing to belonging: Attachment theory, connectedness, and indigenous children in Canada. In S. McKay, D. Fuchs, \& I. Brown (Eds.), Passion for action in child and family services": Voices from the prairies (pp 49. 67). Regina, SK: Canadian Plains Research Center. 
Creswell, J. (2009). Research Design: Qualitative, quantitative and mixed methods approaches. $3^{\text {rd }}$ Edition. Thousand Oaks, CA: Sage Publishers.

Daniels, H. W. (1998). Bill C-3l: The Abocide Bill: Congress of Aboriginal Peoples.

De Souza, M., \& Rymarz, R. (2007). The role of Cultural and spiritual expressions in affirming a sense of self, place and purpose among young Indigenous Australians. International Journal of Children's Spirituality 12(3), 277-288.

Deters, K. (1997). Belonging nowhere and everywhere: Multiracial identity development. Bulletin of the Menninger Clinic, 61(3), 368-391.

Freire, P. (2000). Pedagogy of the oppressed (30th anniversary ed.). New York: Continuum. Frideres, J. (2008). Aboriginal Identity in the Canadian Context. The Canadian Journal of Native Situdies, 28(2), 313-342.

Garrett, M. T., \& Herring, R. D. (2001). Honoring the Power of Relation: Counseling native adults. Journal of Humanistic Counseling, Education and Development. 40, 139-160.

Gecas, V. \& Schwalbe, M.L. (1983). Beyond the Looking-Glass Self: Social Structure and Efficacy-Based Self-Esteem. Social Psychology Quarterly, 46(2), 77-88.

Gehl, L. (2000). The Queen and I: Discrimination against women. Canadian Women Studies, 20(2), 64-69

Germain, E. R. (2004). Culture or race? Phenotype and cultural identity development in minority Australian adolescents. Australian Psychologist, 39(2), 134-142.

Greenwood, M. (2006). Children Are a Gift to Us: Aboriginal-Specific Early Childhood Programs and Services in Canada. Canadian Journal of Native Education, 29(1), 12-28.

Hall, R. (2001). Identity development across the lifespan: a biracial model. Social Science Journal, 38(1), 119-126. 
Indian and Northern Affairs (2009). Backgrounder- McIvor: An Overview. Retrieved June 11, 2010 from http://www.ainc-inac.gc.ca/ai $/ \mathrm{mr} / \mathrm{nr} / \mathrm{m}$-a2009/bk000000338-eng.asp

Information Centre on Aboriginal Health. (2006). Glossary of Terms. Retrieved March 10, 2010 from www.icah.ca/content/en/glossary/terms

Irving, A. \& Young. T. (2002). Paradigm for pluralism: Mikhail Bakhtin and social work practice. Social Work, 47(1), 19-29.

Keddell, E. (2007). Cultural identity and the children, young persons, and their families act 1989: Ideology, policy and practice. Social Policy Journal of New Zealand, 32, 49-71.

Kenny, C., Faries, E., Fiske, J.A., \& Voyageur, C.(2004). A Holistic Framework for Aboriginal Policy Research. In status of women: Government of Canada. Retrieved on February 25, 2010 from http://dsp-psd.pwgc.ca/Collection/SW21-114-2004E.pdf

Lavallee, L. (2007). Physical Activity and Healing through the Medicine Wheel. Journal of Aboriginal and Indigenous Community Health 5(1), 127-153.

Lawrence, B. (2003). Gender, race, and the regulation of Native identity in Canada and the United States: An Overview. Hypatia, 18(2), 3-18.

MacDonald, M. (2000). In Hill J., Harvey L. (Eds.), Theories and methods. London: Hodder \& Stoughton.

Mageo, J. (2008). Zones of ambiguity and identity politics in Samoa. Journal of the Royal Anthropological Institute, 14(1), 61-78

Mcgrath, A., \& Stevenson, W. (1996). Gender, race, and policy: Aboriginal women and the state in Canada and Australia. Labour / Le Travail, 3837-3853.

Miehls, D. (2001). The interface of racial identity development with identity complexity in clinical social work student practitioners. Clinical Social Work Journal, 29(3), 229-244 
Morrison, J. W. \& Bordere, T. (2001). Supporting Biracial Children's Identity Development. Childhood Education, 77(3), 134-138.

Morrisett, V., McKenzie, B., \& Morissette, L. (1993). Toward an aboriginal model of social work practice: Cultural knowledge and traditional practices. Canadian Social Work Review, 10(I), 91-108.

Myers, L.J., Speight, S.L., Highlen, P.S., Cox, C.I., Reynolds, A. L., Adams, E.M., Hanley, C.P. (1991). Identity Development and Worldview: Toward an optimal conceptualization. Journal of Counselling \& Development, 70, 54-63.

Nabigon, H., Hagey, R., Webster, S., \& MacKay, R. (1999). The learning circle as a research method: The trickster and windigo in research. Native Social Work Journal, 2(1), 113137.

Phinney, J. (2008). Bridging Identities and Disciplines: Advances and challenges in understanding multiple identities. New Directions for Child and Adolescent Development, 120,97-109

Public Health Agency of Canada. Aboriginal children: the healing power of cultural identity. Retrieved on March 1, 2010 from http://www.Phac-aspc.gc.ca/dca-dea/programsmes/aboriginal-autochtones-eng.php?option

Punch, K.F. (2009). Developing Effective Research Proposals. Sage Publishing

Rae, J. (2006). Indigenous Children: Rights and Reality. UN Sub-group on Indigenous Children and Young Peoples (ISG). University of Toronto,

Schnarch, B. (2004). Ownership, Control, Access and Possession (OCAP) or Self-Determination Applied Research: A critical analysis of contemporary First Nations research and some options for First Nations communities. Joumal of Aboriginal Health. I(l), 80-95. 
Sedinger, T. (2002). Nation and identification: Psychoanalysis, race, and sexual difference. Cultural Critique 50, 40-73.

Shih, M. (2004). Positive stigma: Examining resilience and empowerment in overcoming stigma. ANNALS, AAPSS, 591, 175-185

Smith, L.T. (2002). Decolonizing methodologies: Research and indigenous peoples. Dunedin: University of Otago Press.

Stevenson, J. (1999). The Circle of Healing. Native Social Work Journal, 2, 8-21.

Takeda, N. \& Williams, J. H. (2008). Pluralism, identity and the state: national education policy towards Indigenous minorities in Japan and Canada. Comparative Education 44(1), $79-91$.

Tricouncil Policy Statement $2^{\text {nd }}$ draft (2009). Research Involving Aboriginal Peoples in Canada (chapter 9). Retrieved on March 24, 2010 from http://www.pre.ethics.gc.ca/eng/policypolique/initiatives/revised-revisee/Default

Vignoles, V. 1., Regalia, C., Manzi, C., Golledge, J., \& Scabini, E. (2006). Beyond Self-Esteem: Influence of Multiple Motives on Identity Construction. Journal of Personality and Social Psychology 90(2), 308-322.

Vodde, R., \& Gallant, J. P., (2002). Bridging the gap between micro and macro practice: Large scale change and a unified model of narrative-deconstructive practice. Journal of Social Work Education, 38(3), 439-458.

Weaver, H. (2001). Indigenous Identity. American Indian Quarterly, 25(2), 240-255.

Wesley-Esquimaux,C. (2007). Inside Looking Out, Outside Looking In. First Peoples Child \& Family Review, 3(4), 62-71. 
Wilson, S. (2001). What is indigenous research methodology? Canadian Journal of Native Education, 252(2), 175-179.

Wilson, S. (2008). Research is Ceremony: Indigenous research methods. Fernwood Publishing, Winnipeg.

United Nations. (2009). Committee on the Rights of the Child, General comment on Indigenous children and their rights under the convention. (Cat No.11). Geneva. 


\section{Glossary}

Aboriginal is a term which recognizes individuals who can trace their ancestry back to the original habitats of Canada. This term is inclusive of Métis, First Nations, and Inuit peoples of Canada regardless of being 'registered' with the government (Information Centre on Aboriginal Health, 2006).

Anishnaabe is a term that is used by the people in the community to describe them. It is an Ojibway and Algonquin term that means human being or person.

Band Membership: Allows First Nations people with status to have treaty rights, the ability to own ancestral lands, and access to programs and support within their community.

Bill-C3I is an act that was created to make amendments to the Indian Act of 1876 . These changes were meant to eliminate sexual discrimination against Aboriginal women in Canada as a result of marriage provisions set out in the Indian Act (Native Women's Association of Canada).

First Nations is a term used in Canada that is used to replace the word Indian, which many find offensive. This word refers to both Status and Non-status 'Indians'.

Indian was a name given to describe all Indigenous people in Canada who are not Inuit or Métis. This term is considered outdated and offensive by many First Nations people. There are three types of Indians: Status, Non-Status, and Treaty Indians (Information Centre on Aboriginal Health, 2006).

Indian Act is a Canadian government piece of legislation enacted in 1876 which governs and regulates the lives of Aboriginal people in Canada. 
Indigenous people are a group of people whose ancestry can be traced back to the original inhabitants of a country, territory or area. This term refers to the original occupants of any country, territory or area (Information Centre on Aboriginal Health, 2006).

Non-Status Indians are people who consider themselves to be First Nations but are not recognized by the Canadian government as having status. This lack of recognition may be due to having lost their status rights or they may be unable to prove identity. Non-status Indians are not eligible or entitled to the rights and benefits which status Indians are (Information Centre on Aboriginal Health, 2006).

Status Indians are people who are have been determined by the Canadian government to be registered as Indians with the Federal Government as defined by the Indian Act. This makes them eligible and entitled to certain rights and benefits (Information Centre on Aboriginal Health, 2006). 6-1: A person who has full status as an Indian in Canada, they are able to pass on their status to their children regardless of marriage to a status Indian or non-status person. 6-2: A person who is recognized by the Indian act as a Status Indian, but is only able to pass on status to children if they marry a 6-1 or 6-2 status Indian.

Indian Band is a group of First Nations people who belong to a specific reserve. The people belonging to this band are governed by their Chief and Council.

On Reserve to live within a First Nation community.

Off Reserve to live outside of First Nation communities, either by choice, membership or by legislation. 
Smudging is a purification ceremony that cleanses and rids the participants of any bad feelings, negative thoughts and allows for healing to happen by the burning of sacred medicines and the waving of this sacred smoke over self and area. 